\title{
Non-protein amino acids in peptide design ${ }^{\mathbb{T}}$
}

\author{
S ARAVINDA $^{\mathrm{a}}$, N SHAMALA ${ }^{\mathrm{a}}$, RITUPARNA S ROY $^{\mathrm{b}}$ and \\ P BALARAM ${ }^{\mathrm{b}, \mathrm{c} *}$ \\ ${ }^{\mathrm{a}}$ Department of Physics, and ${ }^{\mathrm{b}}$ Molecular Biophysics Unit, Indian Institute of \\ Science, Bangalore 560 012, India \\ ${ }^{\mathrm{c}}$ Chemical Biology Unit, Jawaharlal Nehru Centre for Advanced Scientific \\ Research, Jakkur Campus, Jakkur PO, Bangalore 560 064, India \\ e-mail: pb@mbu.iisc.ernet.in
}

\begin{abstract}
An overview of the use of non-protein amino acids in the design of conformationally well-defined peptides, based on work from the author's laboratory, is discussed. The crystal structures of several designed oligopeptides illustrate the use $\alpha$-aminoisobutyric acid (Aib) in the construction of helices, D-amino acids in the design of helix termination segments and ${ }^{\mathrm{D}}$ Pro-Xxx segments for nucleating of $\beta$-hairpin structures. $\beta$ - and $\gamma$-amino acid residues have been used to expand the range of designed polypeptide structures.
\end{abstract}

Keywords. Peptide design; crystal structures; $\mathrm{C}-\mathrm{H} \cdots \mathrm{O}$ hydrogen bond; hybrid peptides; D-amino acids; $\beta$-amino acids.

\section{Introduction}

The 'first principles' approach to the design of polypeptide structures, which adopt welldefined folded conformations, developed at Bangalore, relies on the use of stereochemically constrained amino acids to direct peptide chain folding. ${ }^{1,2}$ The de novo design of polypeptide structures provides insights into the factors that govern the folding of peptides and proteins. The approach is based on the ability of specific non-protein amino acid residues to populate limited regions of conformational space, thereby serving as local nuclei for the propagation of ordered secondary structures. This overview presents the general background to the use of non-protein amino acids as stereochemical directors of polypeptide chain folding and illustrates some recent examples of the design of helices, hairpins and novel structures in sequences of mixed chirality. Recent work, which addresses the issue of enhancing the repertoire of polypeptide structures by incorporating $\beta$ and $\gamma$ amino acid residues, is also highlighted.

\section{Stereochemistry of polypeptide chains}

Forty years have passed since the principles of polypeptide conformational analysis were first enunciated by GN Ramachandran and his colleagues at the University of Madras. ${ }^{3}$ The Ramachandran plot provides a remarkably powerful and convenient means for assigning the 'stereochemical allowedness' of the local conformations of individual

\footnotetext{
IIDedicated to Professor C N R Rao on his 70th birthday

*For correspondence
} 
amino acid residues in polypeptide and protein structures. The variables used in the construction of the Ramachandran $(\phi, \psi)$ plot are the two torsion (dihedral) angles $\phi$ and $\psi$, which correspond to rotations about the two single bonds at each residue in the polypeptide chain, $\mathrm{N}-\mathrm{C}^{\alpha}(\phi)$ and $\mathrm{C}^{\alpha}-\mathrm{C}(\psi)$. The two-dimensional $\phi \psi$ plot simplifies the problem of considering three-dimensional chain folding in analytical terms. The regular structures of polypeptide $\alpha$ amino acid chains, the $\alpha$ helix and $\beta$-sheet were first recognised by Linus Pauling, a little over half a century ago. ${ }^{4}$ In the Ramachandran representation, an idealised secondary structure, generated by repetition of the $\phi \psi$ dihedral angles along the chain, is simply a single point in $\phi \psi$ space. The allowed regions of conformational space were generated by Ramachandran's group assuming the simple hard sphere contact criterion, which simply states that two proximal non-bonded atoms cannot approach one another at distances less than the sum of their van der Waals radii. Figure 1a shows a view of the classical Ramachandran plot for the L-alanine residue, with the regions of major regular structures indicated. ${ }^{3,5,6}$ It is clear that almost two thirds of $\phi \psi$ space is strictly disallowed for L-Ala, the prototype chiral amino acid. This map is broadly representative of the allowed regions for 18 of the 20 amino acids
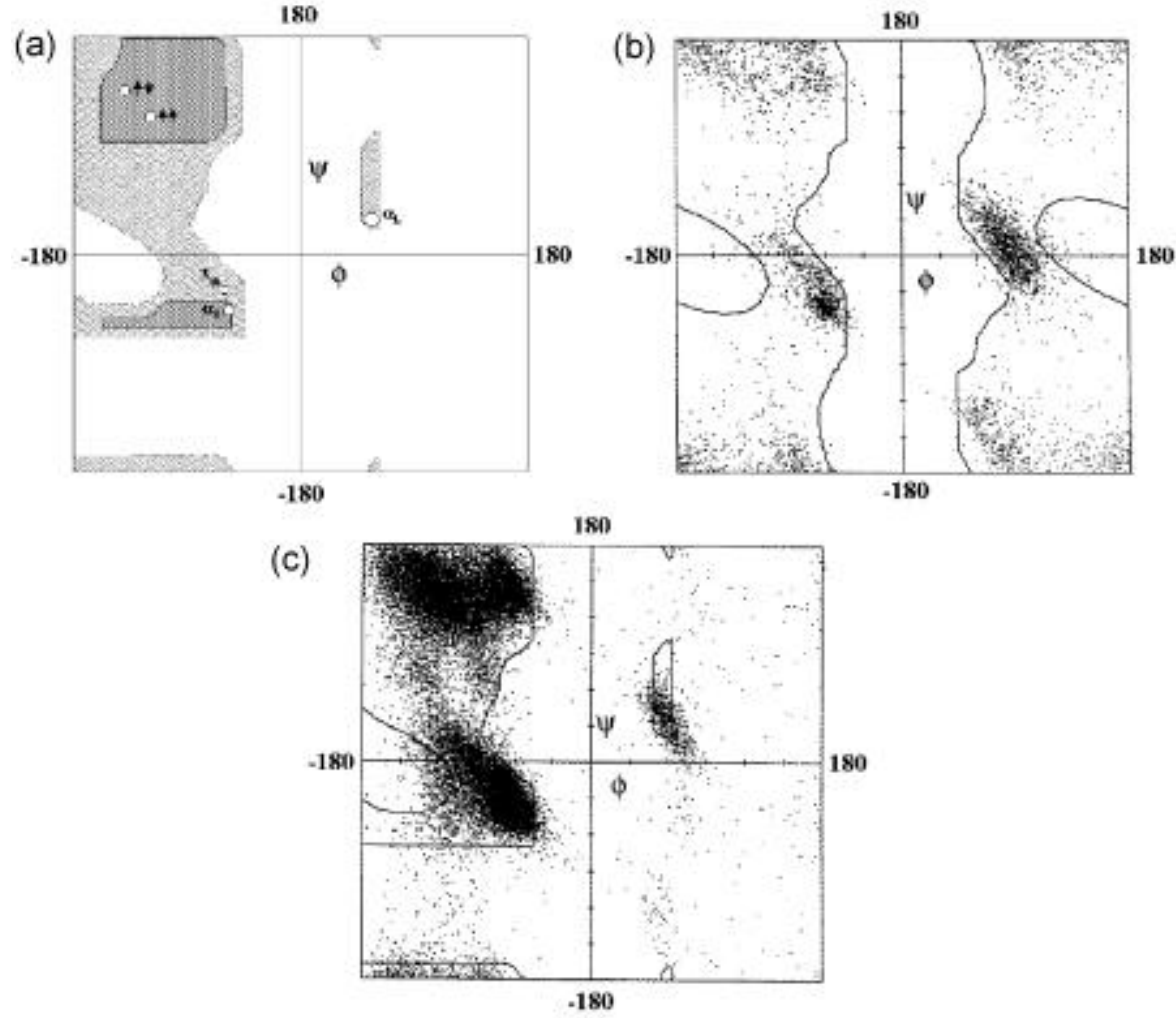

Figure 1. (a) Ramachandran map for $\mathrm{N}$-acetyl-L-Ala-N'-methylamide. The shaded regions are stereochemically allowed. Regions corresponding to $3_{10}, \alpha$-helical and parallel ( $\uparrow$ ) and antiparallel ( $\downarrow \downarrow) \beta$-sheets are indicated. (b) Distribution of $\phi, \psi$ values of Gly residues from 250 protein structures $(\leq 2 \cdot 0 \AA$ resolution) (ref. $7 \mathrm{~b})$. (c) Distribution of non-Gly residues from 250 protein structures (ref. $7 \mathrm{~b}$ ). 
that occur in proteins, the exceptions being glycine and proline. For Gly, the sole achiral residue in proteins, which lacks a substitutent at the $\mathrm{C}^{\alpha}$ atom, the allowed regions of $\phi \psi$ space are considerably larger and symmetrically disposed with respect to the origin (figure 1b). The distribution of experimentally determined $\phi \psi$ values for individual residues in high resolution protein structures, 47612 residues from 250 proteins, is shown in figure 1c. Clearly, the experimental observations closely correspond to the allowed regions anticipated by Ramachandran. A similar distribution for Gly residues is illustrated in figure 1b. Notably, for this achiral residue the observed distribution is spread in all four quadrants of the $\phi \psi$ map. $^{7}$ Inspection of figures $1 \mathrm{~b}$ and $\mathrm{c}$ reveals that alkylation at the $\mathrm{C}^{\alpha}$ atom dramatically reduces the allowed regions of conformational space, on going from Gly to L-Ala. By extrapolation, further alkylation, as in the $\mathrm{C}^{\alpha, \alpha}$ dialkylated residue $\alpha$ aminoisobutyric acid (Aib) $\left[\mathrm{H}_{2} \mathrm{~N}-\mathrm{C}\left(\mathrm{CH}_{3}\right)_{2}-\mathrm{COOH}\right]$, would result in a greater restriction of the allowed conformational space. In principle, the allowed regions for the Aib residue can be generated by overlapping the Ramachandran maps for L-Ala and D-Ala (figure 2a). ${ }^{8}$ It is apparent that only small regions that correspond to the right- and left-handed helical structures are indeed allowed for this residue. ${ }^{9,10}$

\section{3. $\alpha$-Aminoisobutyric acid and helix nucleation}

Aib is a naturally occurring amino acid, which is widely distributed in polypeptide antibiotics produced by diverse species of soil fungi. Interestingly, Aib and its homolog isovaline (Iva) $\left[\mathrm{H}_{2} \mathrm{~N}-\mathrm{C}\left(\mathrm{CH}_{3}\right)\left(\mathrm{C}_{2} \mathrm{H}_{5}\right)-\mathrm{COOH}\right]$ are components of the amino acid mixtures found in meteorites and have been used as an indicator of the extraterrestrial origin of rock samples. ${ }^{11}$ The peptaibol class of antibiotics produced by several fungal strains are characterised by a high proportion of Aib residues in the sequence and a C-terminal alcohol moiety. A very large number of peptaibol antibiotics have thus far been characterised $^{12}$ and the crystal structures of alamethicin, ${ }^{13}$ zervamicin, ${ }^{14}$ and antiamoebin ${ }^{15,16}$ have been determined. The structures of the natural peptides are largely helical even
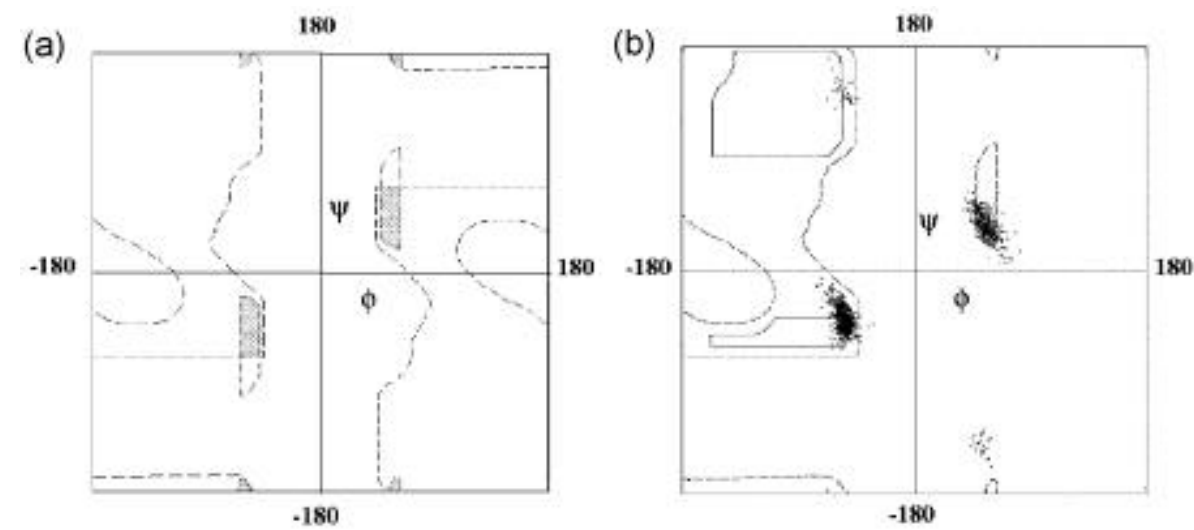

Figure 2. (a) Overlapped Ramachandran maps for N-acetyl-L-Ala-N'-methylamide and $\mathrm{N}$-acetyl-D-Ala-N'-methyamide. The shaded regions are stereochemically allowed for both L- and D-Ala. (b) Distribution of the observed conformations of $1104 \mathrm{Aib}$ residues in 367 independent crystal structures. (Coordinates for peptide structures have been obtained from the Cambridge Crystallographic Data Centre, ref. 72.) 
when the sequences are interspersed with several Pro/Hyp residues; testimony to the helix promoting properties of the Aib residue. Interest in the structural chemistry of the peptaibol antibiotics has stemmed from the fact that they form voltage gated ion channels across artificial lipid bilayers. ${ }^{17}$

The stereochemical consequences of introducing Aib into peptide chains was first established at Bangalore, with the crystal structure determination and solution spectroscopic studies of the N-terminus tetrapeptide sequence of alamethicin. ${ }^{18}$ This was followed by the establishment of a $33_{10}$-helical conformation for the Aib oligopeptide Tosyl-(Aib) ${ }_{5}-\mathrm{OMe}$ in crystals. ${ }^{19}$ Almost concurrently, results of investigations of Aib containing sequences corresponding to fragments of peptaibol antibiotics appeared from the groups of Garland Marshall (St Louis) ${ }^{20}$ and Gunther Jung (Tubingen), ${ }^{21}$ providing strong support for the helix forming properties of Aib residues. It was quickly realised that the introduction of Aib residues into polypeptide chains limits the range of accessible conformations; nucleates of $\beta$-turns and helical structures and facilitates crystallisation presumably by restricting conformational flexibility in solution. Over the last 20 years a very large number of Aib containing peptides crystal structures have been determined, primarily by groups at Bangalore, Washington (Isabella L Karle) and Padova (Claudio Toniolo), which have provided valuable insights into the nature of helical conformations, helix packing in crystals, helix hydration, $3_{10}$ / $\alpha$ helical transitions and the role of intramolecular hydrogen bonds in helix stabilisation. The extensive work on Aib peptides has resulted in the accumulation of a large body of information on polypeptide conformations. $^{1,2,22}$ Figure $2 \mathrm{~b}$ shows the distribution of the observed $\phi \psi \psi v$ values for Aib, representing 1104 residues from 367 independent crystal structures. A dramatic concentration of $\phi \psi$ values in the right $\left(\alpha_{R}\right)$ and left handed $\left(\alpha_{E}\right)$ helical regions emphasizes the great propensity of Aib residues to occur in helical conformations. In the following section we briefly consider some specific issues related to helical structures in polypeptides.

\section{4. $\quad 3_{10}$ and $\alpha$-helical structures}

Figure 3 illustrates the molecular conformation in crystals observed in three representative Aib containing decapeptides. The Aib oligomer pBrBz-(Aib) $)_{10}-\mathrm{OtBu}$ adopts an almost perfect $3_{10}$ helical conformation stabilised by eight intramolecular $4 \rightarrow 1$ hydrogen bonds. ${ }^{23}$ The decapeptide Boc-Aib-(Ala-Leu-Aib) $)_{3}-$ OMe adopts a mixed $3_{10} /$ othelical structure with $4 \rightarrow 1$ hydrogen bonds $\left(3_{10}\right)$ favored at the $\mathrm{N}$-terminus and $5 \rightarrow 1$ hydrogen bonds $(\alpha)$ occurring at the C-terminus. ${ }^{24}$ The decapeptide Boc-Leu-Aib-ValAla-Leu-Aib-Val-Ala-Leu-Aib-OMe adopts an almost perfect $\boldsymbol{\alpha}$ helical conformation stabilised by seven intramolecular $5 \rightarrow 1$ hydrogen bonds. ${ }^{25}$ Table 1 summarises the potential $4 \rightarrow 1$ and $5 \rightarrow 1$ hydrogen bond parameters, which permit the choice of the interaction corresponding to either $3_{10}$ or $\alpha$ helical structures. It must be emphasised that the distinction between $3_{10}$, $\alpha$ and mixed helical structures is generally based only on the choice of the intramolecular hydrogen bond type. Relatively small variations in $\phi \psi$ dihedral angles can result in switching of $4 \rightarrow 1$ and $5 \rightarrow 1$ hydrogen bonds. In helices the $\mathrm{N} \cdots \mathrm{O}$ distances for both $4 \rightarrow 1$ and $5 \rightarrow 1$ hydrogen bonds can lie within acceptable limits $(\leq 3.5 \AA)$. It is therefore necessary that the complete characterisation of the donor acceptor geometries are carried out before choosing the type of hydrogen bond. ${ }^{26}$ There has been considerable discussion in the literature on the relative stabilities of 310 and $\propto$ helical structures in Aib containing peptides. ${ }^{27}$ The general consensus that has 
emerged is that in Aib oligomers, $3_{10}$ helices are favoured. In sequences, which contain relatively few Aib residues, mixed $3_{10}$ / $\alpha$ helical structures and $\alpha$ helical structures appear to be prominent. ${ }^{22 \mathrm{c}}$ A survey of a large body of helical structures does not reveal any readily apparent correlation between the Aib content and positioning in the sequence, in the case of peptides having fewer than $50 \%$ Aib residues. In several crystal structures, multiple helical molecules have been observed in the crystallographic asymmetric unit, which adopt different hydrogen bonding patterns. ${ }^{22 c, e, f, 28}$ It appears that the activation barriers required for the transformation of $3_{10}$ helical turns into $\alpha$ helical turns is small, facilitating facile interconversion in solution. Attempts to establish diagnostic spectroscopic criteria, for example CD band shapes and positions ${ }^{29}$ are likely to be complicated by dynamic interconversions between heterogeneous helical structures. The crystalline state may be viewed as providing a snapshot of specific of the molecular conformations that are present in solution, often entrapping a single distinct molecular species. The observation of multiple helical forms in crystals underscores the fact that the molecules probably exist in a broad potential well, with very small barriers separating various helical forms.

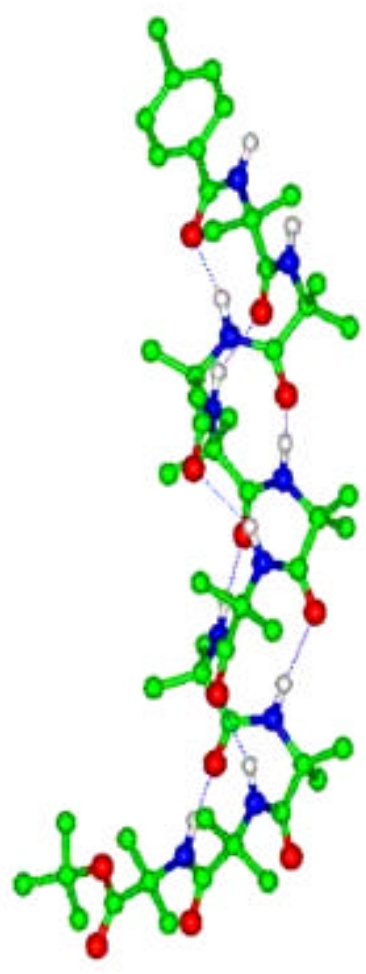

a

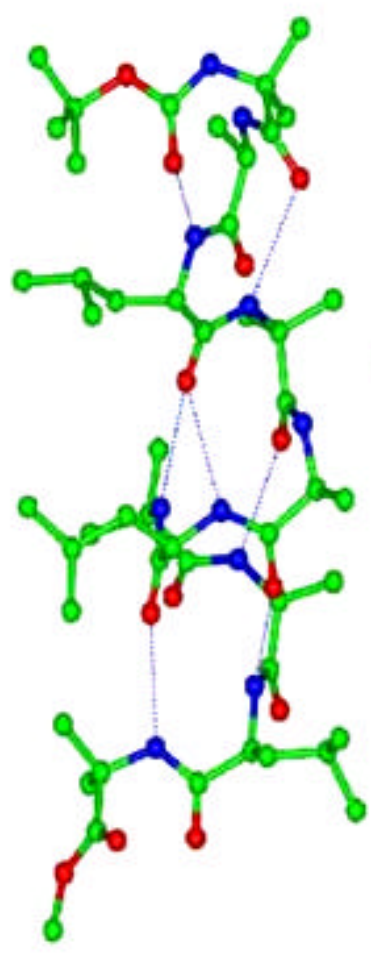

b

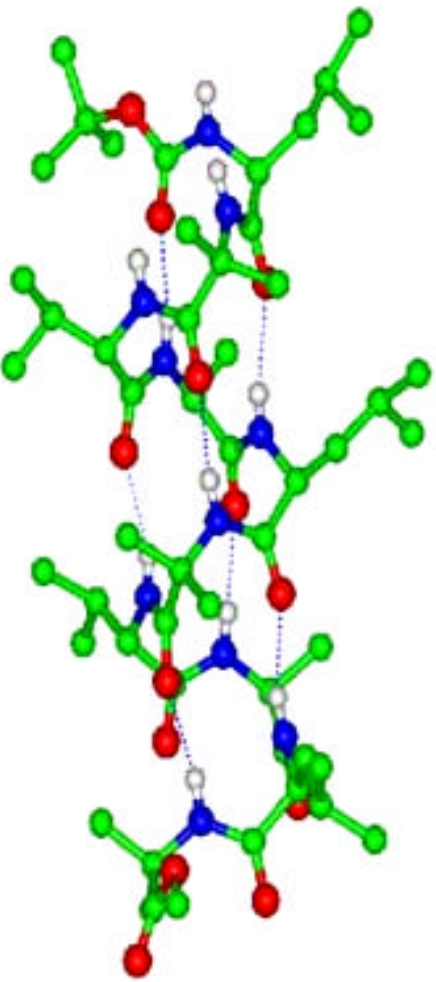

c

Figure 3. Molecular conformations observed in the crystals for three synthetic decapeptides (a) pBrBz-(Aib) $10-\mathrm{OtBu}, 3_{10}$-helix (ref. 23). (b) Boc-Aib-(Ala-LeuAib) ${ }_{3}-\mathrm{OMe}, 3_{10} / \alpha$ helix (ref. 24). (c) Boc-Leu-Aib-Val-Ala-Leu-Aib-Val-AlaLeu-Aib-OMe, $\alpha$-helix (LAL10, ref. 25). Dotted lines represent intramolecular hydrogen bonds. 


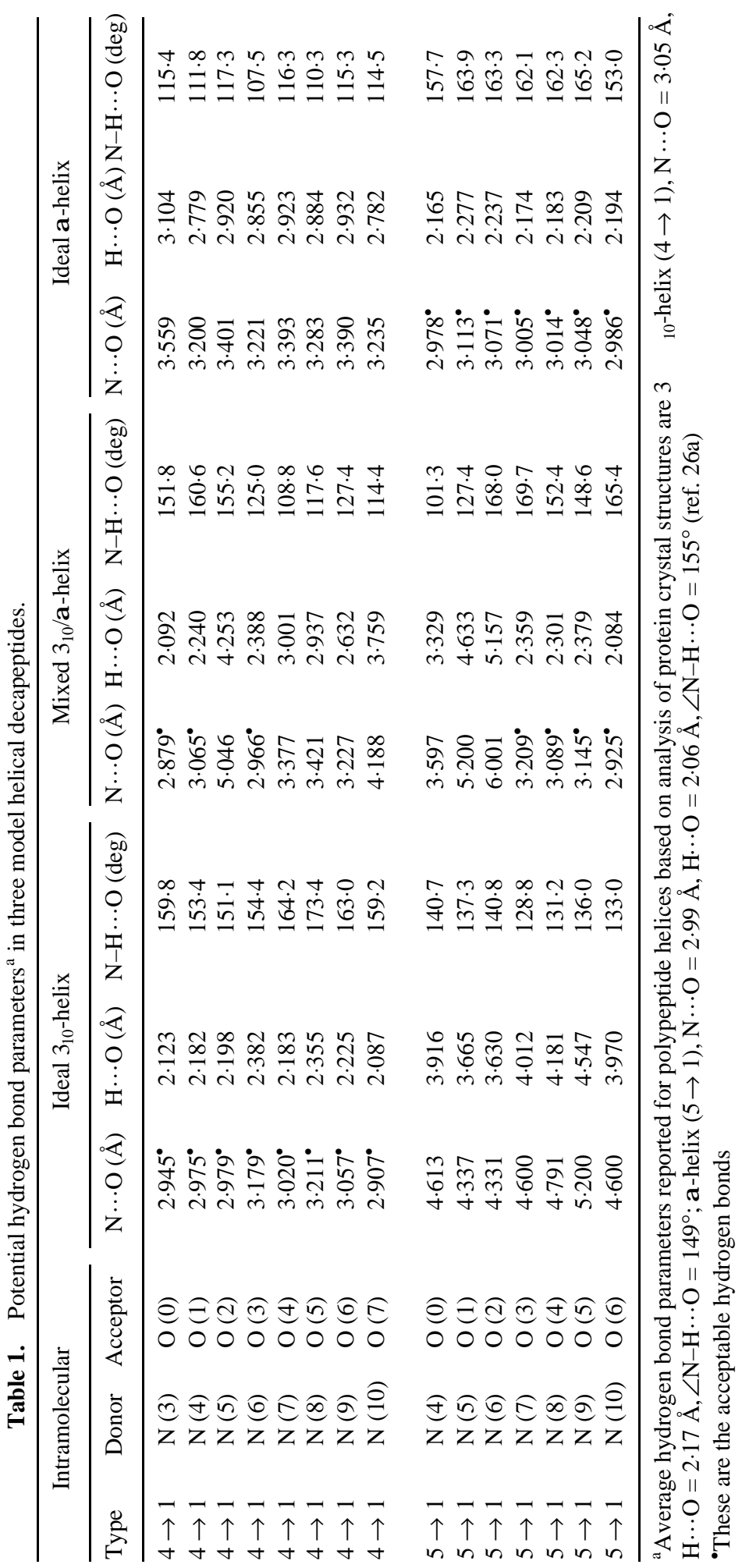




\section{Helix-terminating motifs}

The ability to synthetically construct defined helical peptide modules has permitted structural investigation of helix-terminating motifs. In proteins, right-handed $\alpha$ helical segments often terminate with a residue adopting the left-handed helical $\left(\alpha_{\mathrm{E}}\right)$ conformation (Schellman motif). ${ }^{30}$ The achiral residue Gly has the greatest propensity to occur at the terminating $(\mathrm{T})$ position. In helical peptides containing an achiral Aib residue at the penultimate position from C-terminus, formation of Schellman motifs, with Aib adopting an $\alpha_{\varepsilon}$ conformation, has been frequently observed. ${ }^{31}$ In these structures, pairs of hydrogen bonds $6 \rightarrow 1$ and $4 \rightarrow 1$ stabilise the helix terminating motif (figure 4 ).

As a part of a program to construct synthetic sequences containing multiple elements of secondary structure, we examined approaches to terminate helices at the C-terminus end. The introduction of D-amino acid residues, which favour $\alpha_{\varepsilon}$ conformations should facilitate helix termination. Figure 5 shows the molecular conformation in crystals of the decapeptide Boc-Leu-Aib-Val-Ala-Leu-Aib-Val- ${ }^{\mathrm{D}}$ Ala- ${ }^{\mathrm{D}}$ Leu-Aib-OMe, (LAD10), which possesses two contiguous D-residues at positions 8 and 9 . As anticipated, the righthanded helix formed by residues 1 to 7 terminated with ${ }^{\mathrm{D}} \mathrm{Ala}(8)$ adopting an $\alpha_{\mathrm{L}}$ conformation, generating a Schellman motif. However, this structure revealed an unanticipated feature with polypeptide chain reversal occurring over the C-terminus segment, residues 8 to 10 , stabilised by an unusual $\mathrm{C}-\mathrm{H} \cdots \mathrm{O}$ hydrogen bond between $\mathrm{Ala}(4) \mathrm{C}^{\alpha} \mathrm{H}$ and ${ }^{\mathrm{D}} \mathrm{Leu}(9) \mathrm{CO}$ groups. ${ }^{32}$ An almost identical conformation is also established in crystals of the analog peptide LGD10, where Ala(4) is replaced by Gly. In this case, the intramolecular $\mathrm{C}-\mathrm{H} \cdots \mathrm{O}$ hydrogen bond involved the pro $R$ hydrogen of the Gly residue. ${ }^{33}$

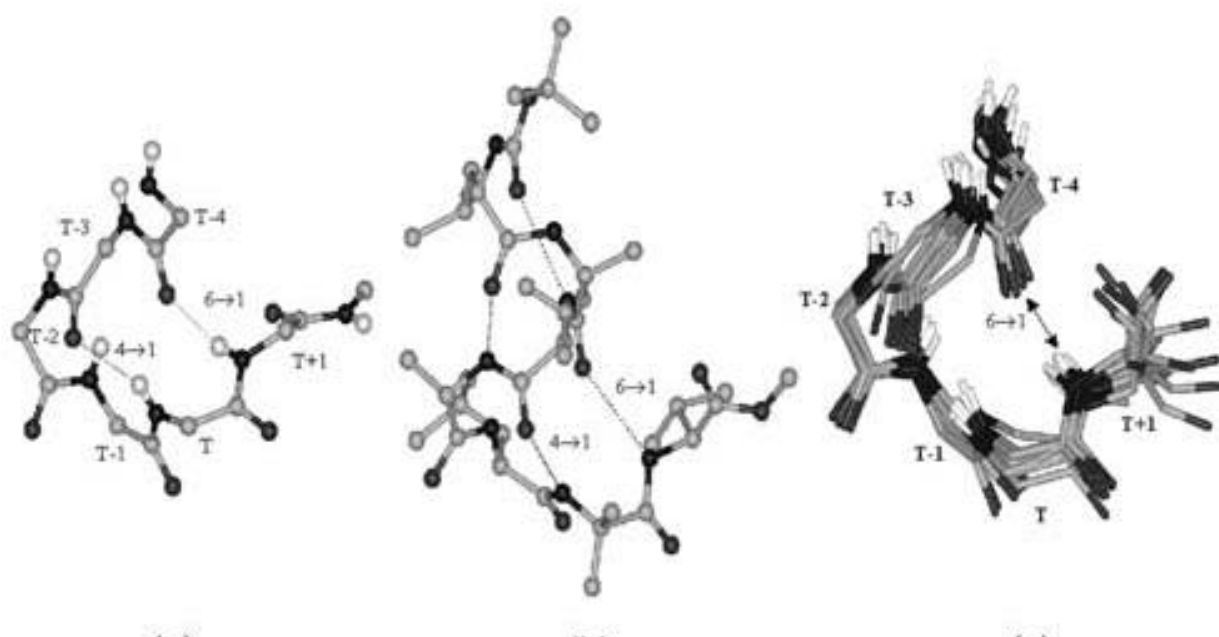

(a)

(b)

(c)

Figure 4. (a) Helix terminating Schellman motif stabilized by a pair of $4 \rightarrow 1$ and $6 \rightarrow 1$ hydrogen bonds. Residue T is the helix terminating residue. Residue T- 1 to T-4 form the C-terminus of the helix. (b) Molecular conformation in crystals for the peptide Boc-Leu-Aib-Val-Ala-Leu-Aib-Val-OMe (ref. 31c). Note the formation of the Schellman motif. Aib(6) adopts an $\alpha_{L}$ conformation and is the terminating residue T. (c) An overlay of helix terminating Schellman motifs observed in 18 crystal structures of helical peptides. 


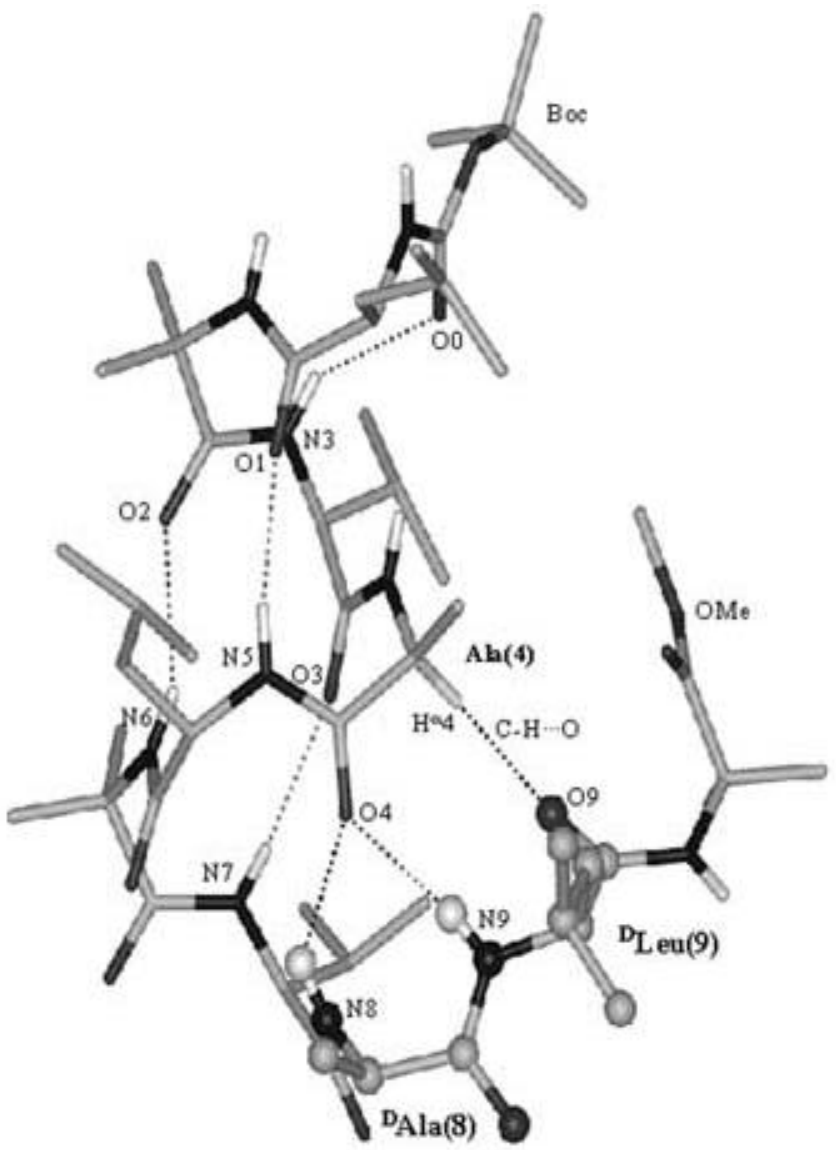

LAD10

Figure 5. Molecular conformation of the decapeptide Boc-Leu-Aib-Val-Ala-LeuAib-Val- ${ }^{\mathrm{D}} \mathrm{Ala}-{ }^{\mathrm{D}} \mathrm{Leu}-\mathrm{Aib}-\mathrm{OMe}$ (LAD10, ref. 32) observed in crystals. Note the formation of the $\mathrm{C}-\mathrm{H} \cdots \mathrm{O}$ hydrogen bond between $\mathrm{Ala}(4) \mathrm{C}^{\alpha} \mathrm{H}$ and ${ }^{\mathrm{D}} \mathrm{Leu}(9) \mathrm{CO}$ groups.

Figure 6a shows the superposition of peptides LAD10 and LGD10 (RMSD $=0.54 \AA$ for all the back bone atoms). A notable feature of this unusual motif is that it appears to facilitate registry of antiparallel helix and strand segments, stabilised by backbone $\mathrm{C}-\mathrm{H} \cdots \mathrm{O}$ hydrogen bonds. A search of 634 high resolution protein structures revealed the occurrence of a similar motif in proteins. Figure $6 \mathrm{~b}$ shows the superposition of 15 examples from protein structures on the structure of peptide LAD10. ${ }^{34}$ The role of the $\mathrm{C}-\mathrm{H} \cdots \mathrm{O}$ hydrogen bond in facilitating the novel chain reversal in peptides LAD10 and LGD10 has been established by determining the structures of two peptide analogs BocLeu-Aib-Val- ${ }^{\mathrm{D}} \mathrm{Ala}-\mathrm{Leu}-\mathrm{Aib}-\mathrm{Val}-{ }^{\mathrm{D}} \mathrm{Ala}-{ }^{\mathrm{D}} \mathrm{Leu}-\mathrm{Aib}-\mathrm{OMe}$ (DA10) and Boc-Leu-AibVal-Aib-Leu-Aib-Val- ${ }^{\mathrm{D}}$ Ala- ${ }^{\mathrm{D}} \mathrm{Leu}-\mathrm{Aib}-\mathrm{OMe}$ (LUD10). ${ }^{31}$ In these two cases, the pro $R$ $\mathrm{C}^{\alpha} \mathrm{H}$ at T-4 has been replaced by a methyl group. Figure 7 shows a view of the molecular conformation of DA10 and LUD10 in crystals. Interestingly, both the peptides adopt conformations which are completely distinct from those observed for LAD10 and 
LGD10, underscoring the importance of the interaction involving the T-4 $\mathrm{C}^{\alpha} \mathrm{H}$ group in determining the overall fold of the molecule. This example illustrates the role of a relatively long-range backbone interaction in determining peptide folding.

\section{Residue and helix chirality}

The availability of crystalline helical peptides generated by introducing Aib residues into sequences of L-amino acids has permitted the creation of novel backbone folds, which are not observed in protein structures. Figure 8 illustrates the crystal structures of two enantiomeric 14 residue peptides, generated by fusing helical sequences of opposite chirality. The peptides Boc-D-(Val-Ala-Leu-Aib-Val-Ala-Leu)-L-(Val-Ala-LeuAib-Val-Ala-Leu)-OMe (DL14) ${ }^{35}$ and Boc-L-(Val-Ala-Leu-Aib-Val-Ala-Leu)-D(Val-Ala-Leu-Aib-Val-Ala-Leu)-OMe $\left(\right.$ LD14) ${ }^{36}$ were synthesised by condensation of the helical module Boc-Val-Ala-Leu-Aib-Val-Ala-Leu-OMe (UV7), ${ }^{37}$ and its enantiomer. Notably, the two enantiomeric 14 residue sequences crystallise in polymorphic forms DL14 (space group $=P 4_{3}$ ); LD14 (space group $=P 2_{1}$, two molecules in the asymmetric unit); providing a view of three independent 'ambidextrous' structures. Figure 9 shows a schematic ribbon diagram of this unusual fold. The view down the helix

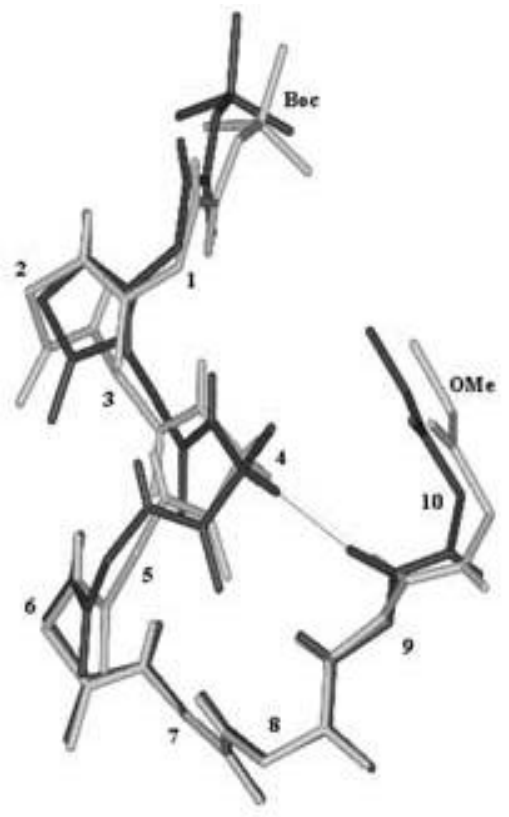

(a)

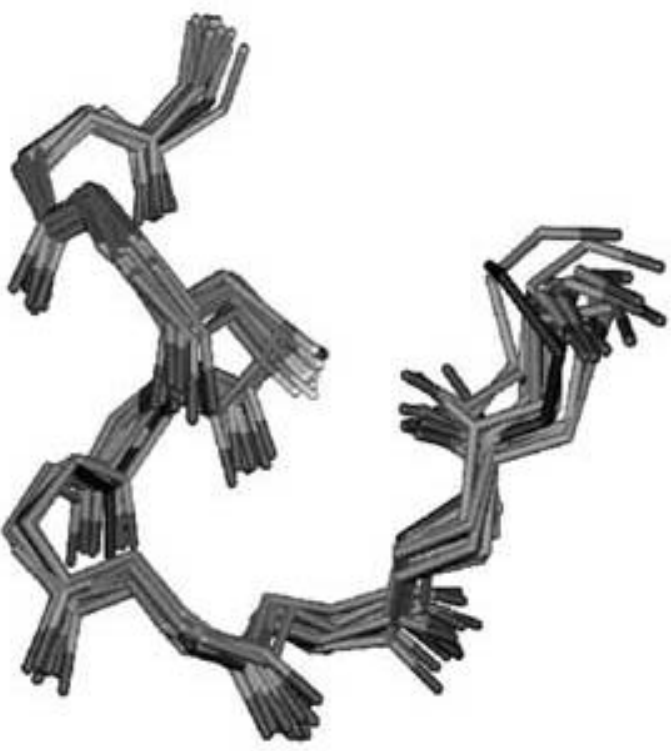

(b)

Figure 6. (a) Superposition of the crystal state conformations of the peptides BocLeu-Aib-Val-Ala-Leu-Aib-Val- ${ }^{\mathrm{D}}$ Ala- ${ }^{\mathrm{D}} \mathrm{Leu}-\mathrm{Aib}-\mathrm{OMe}$ (LAD10) and Boc-LeuAib-Val-Gly-Leu-Aib-Val- ${ }^{\mathrm{D}} \mathrm{Ala}-{ }^{\mathrm{D}} \mathrm{Leu}-\mathrm{Aib}-\mathrm{OMe}$ (LGD10), (ref. 33). (b) Overlay of $15 \mathrm{C}-\mathrm{H} \cdots \mathrm{O}$ hydrogen bond stabilised helix terminating motifs observed in protein structures with LAD10 (ref. 34a). 


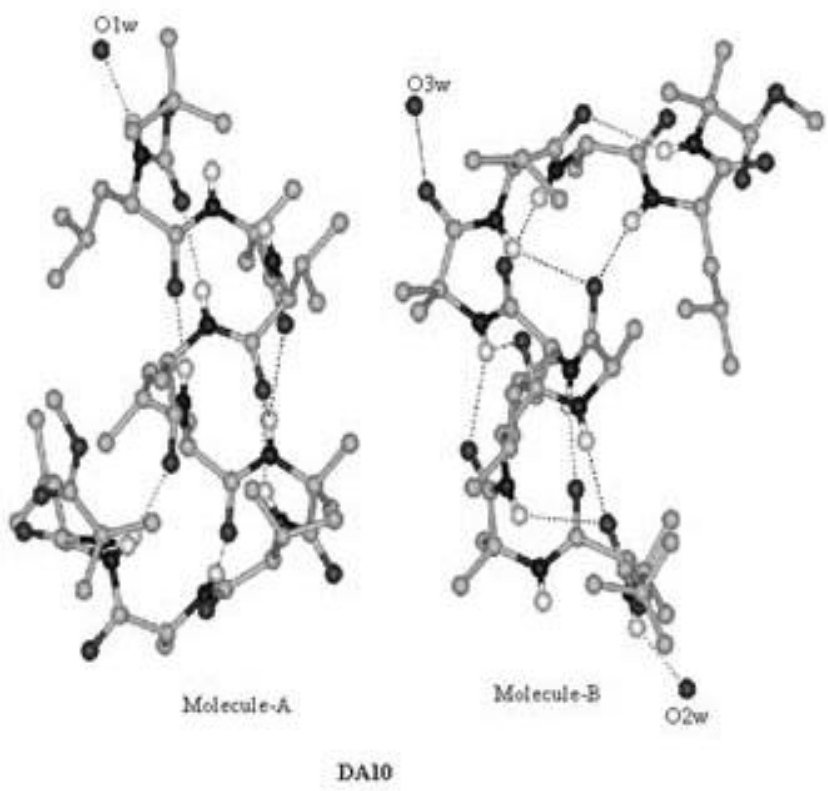

(a)

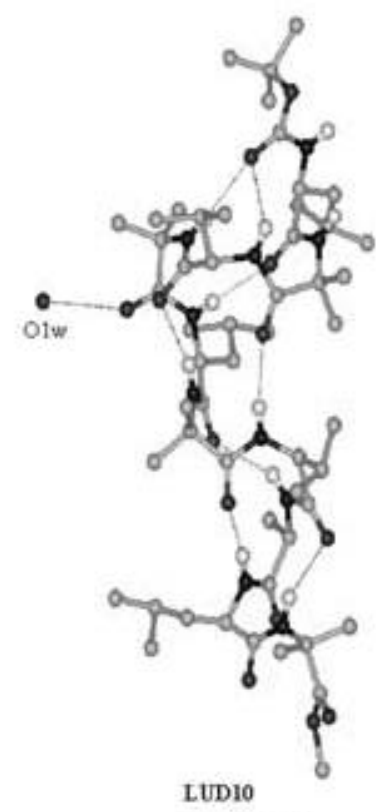

(b)

Figure 7. Molecular conformation in crystals for two synthetic decapeptides (a) Boc-Leu-Aib-Val- ${ }^{\mathrm{D}} \mathrm{Ala}-\mathrm{Leu}-\mathrm{Aib}-\mathrm{Val}-{ }^{\mathrm{D}} \mathrm{Ala}-{ }^{\mathrm{D}} \mathrm{Leu}-\mathrm{Aib}-\mathrm{OMe}$ (DA10). Two molecules are observed in the crystallographic asymmetric unit. (b) Boc-Leu-Aib-ValAib-Leu-Aib-Val- ${ }^{\mathrm{D}} \mathrm{Ala}-{ }^{\mathrm{D}} \mathrm{Leu}-\mathrm{Aib}-\mathrm{OMe}$ (LUD10). Note the difference in the observed structures of these peptides as compared to the decapeptides illustrated in figure $6 a$.

axis illustrates the lateral displacement of the two helices. At the chiral junction, the fusion of $\mathrm{N}$ - and $\mathrm{C}$-terminal helices of opposite hands is mediated through the formation of a Schellman motif. While polypeptides containing fused helical segments of opposite chirality have no natural analog at present, the possibility that such structures may find application is enhanced by recent studies of chiral conflict in synthetic polymers. ${ }^{38}$

The introduction of single D-amino acids or double D-segments into L-amino acid sequences has been anticipated to destabilise right handed helical structures. In the highly stable helical folds nucleated by Aib residues, D-amino acids can be accommodated into $\alpha_{k}$ conformations and conversely L-amino acids can be induced to adopt $\alpha_{\mathcal{L}}$ conformations. The recent crystal structure determinations of predominately L-amino acid sequences containing guest D-residues illustrate this point. Figure 10 shows the molecular conformation of a 13-residue peptide Boc-Leu-Aib-Val-Ala-Leu-Aib-Val- ${ }^{\mathrm{D}} \mathrm{Ala}-$ ${ }^{\mathrm{D}}$ Leu-Aib-Leu-Aib-Val-OMe (LUV13). In this case the double D-segment ${ }^{\mathrm{D}} \mathrm{Ala}-{ }^{\mathrm{D}}$ Leu is comfortably accommodated in a continuous right handed helical structure $\left[{ }^{\mathrm{D}} \mathrm{Ala}(8)\right.$ $\phi=-49 \cdot 3^{\circ}, \psi=-48 \cdot 9^{\circ}$; $\left.{ }^{D} \operatorname{Leu}(9) \quad \phi=-56 \cdot 1^{\circ}, \psi=-54 \cdot 9^{\circ}\right] .{ }^{39}$ In the structure of decapeptide DA10 (figure 7a) the ${ }^{\mathrm{D}} \mathrm{Ala}(4)$ residue occurs in an $\alpha_{k}$ conformation $\left[\phi=-46 \cdot 6^{\circ}, \psi=\right.$ $-52.9^{\circ}$ for molecule A and $\phi=-54 \cdot 1^{\circ}, \psi=-48 \cdot 6^{\circ}$ for molecule B] with the segment residues 1 to 7 forming a conventional right handed helix. In the decapeptide LUD10 (figure $7 \mathrm{~b}$ ), the $\mathrm{N}$-terminal helix terminates at $\mathrm{Aib}(6)$ with the segment 6 to 9 residue 
forming left handed helix. ${ }^{\mathrm{L}} \operatorname{Val}(7)$ adopts an $\alpha_{\mathrm{E}}$ conformation $\left[\phi=42 \cdot 5^{\circ}, \psi=40 \cdot 0^{\circ}\right]$. These examples point to the use of designed host helical sequences in investigating the effect of introduction of guest residues of opposite chirality.

\section{D-Proline and the nucleation of $\beta$-hairpins}

The recognition that the introduction of local conformational constrains can induce the formation of well defined structures in oligopeptides suggests that stereochemical control over polypeptide chain folding may be achieved by judicious introduction of amino acids

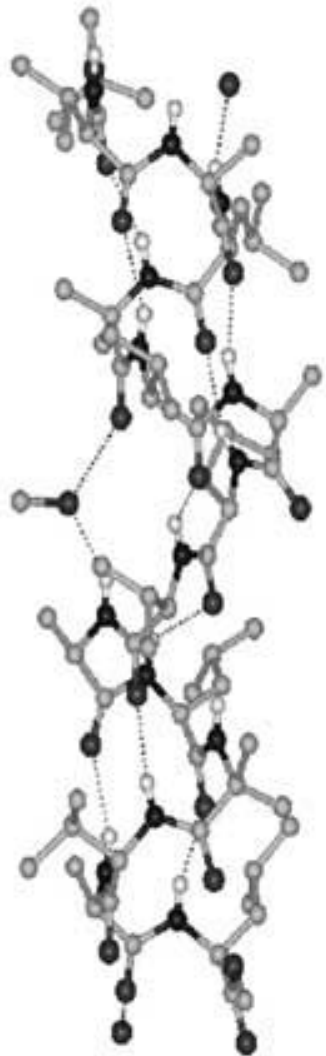

DL14

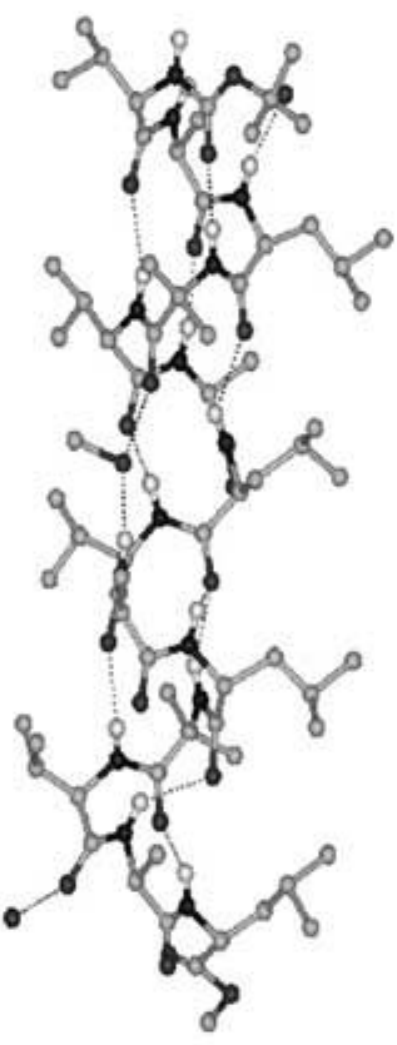

LD14 (A)

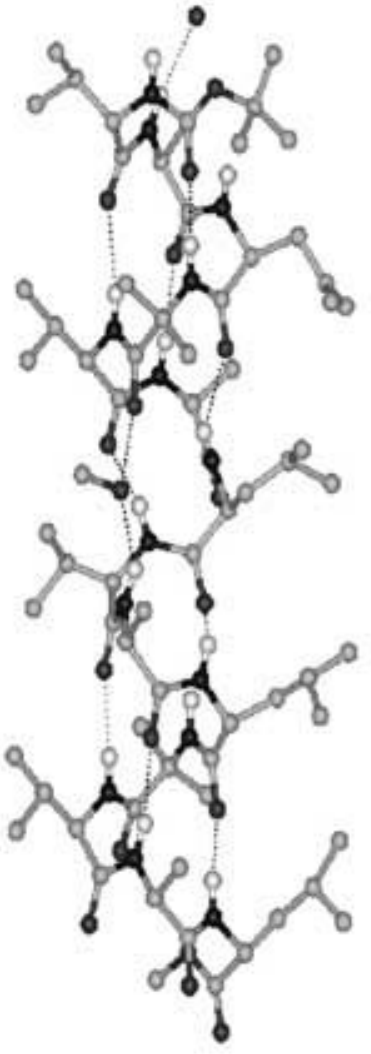

LD14 (B)

(a)

(b)

Figure 8. Molecular conformation in crystals observed for peptide sequences containing fused segments of opposite chirality. (a) Boc-D-(Va-Ala-Leu-Aib-VaAla-Leu)-L-(Val-Ala-Leu-Aib-Val-Ala-Leu)-OMe (DL14). (b) Boc-L-(Va-AlaLeu-Aib-Val-Ala-Leu)-D-(Val-Ala-Leu-Aib-Val-Ala-Leu)-OMe (LD14). Two molecules observed in the asymmetric unit are shown. In all cases, hydration is observed at the centre of the molecule corresponding to the chiral junction (refs 35 , $36)$. 


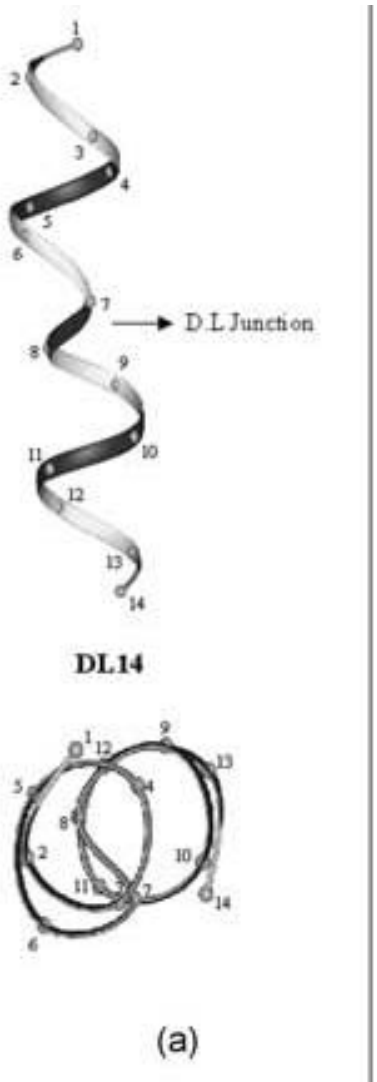

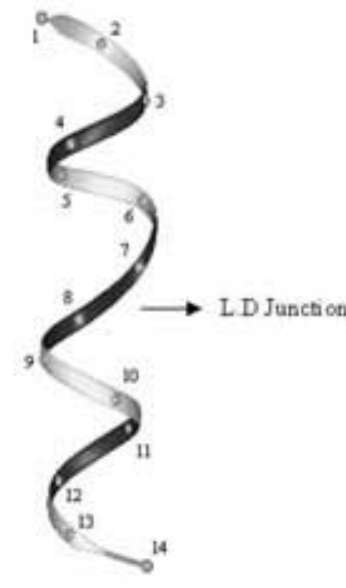

L.D14 Malecule -A

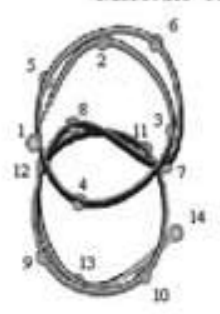

(b)

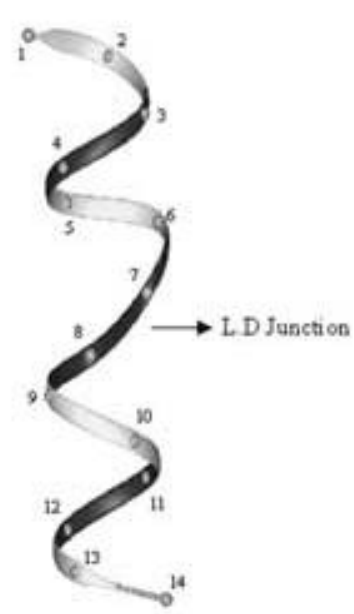

LD14

Molecule-B

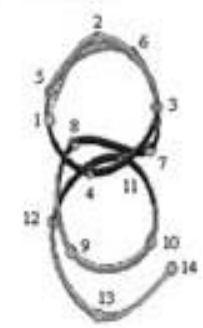

Figure 9. Ribbon representation of the ambidextrous helices shown in figure 8 . (Top) View perpendicular to helix axis. (bottom) View down the helix axis showing the lateral displacement of the helical segments.

with definite conformational properties, into host L-amino acid sequences. This principle has been illustrated in the preceding section for the design of helical peptides. The $\beta$-hairpin constitutes a simple structural motif in which two antiparallel strands are stabilised by cross-strand hydrogen bonds. An analysis of protein structures by Janet Thornton and her colleagues suggested that hairpins in proteins are often nucleated by two residue $\beta$-turns (tight turns). ${ }^{40}$ Most frequently, $\beta$-turns of type II' or I' form the nucleus for chain reversal. The 'prime' turns require a positive $\phi$ value $\left(\approx+60^{\circ}\right)$, for the $i+1$ residue. In proteins, Gly often occupies this position. The other residue predominately found is Asn, which has a fairly high propensity for adopting conformations with positive $\phi v a l u e s .{ }^{41}$ In synthetic design it is necessary to fix the stereochemistry of the turn segment in order to nucleate antiparallel hairpins. Figure 11a shows the allowed region of the Ramachandran map for ${ }^{\mathrm{L}}$ Pro and ${ }^{\mathrm{D}}$ Pro. In these residues, constraints of pyrrolidine ring formation restrict the value of $\phi$ to a narrow band, centred around $60^{\circ}$. The preferred $\phi$ value for ${ }^{\mathrm{L}}$ Pro is $-60^{\circ} \pm 20^{\circ}$, while in ${ }^{\mathrm{D}}$ Pro the corresponding value is $+60^{\circ} \pm 20^{\circ}$. Figure $11 \mathrm{~b}$ summaries the observed conformation for proline residues in a representative dataset of proteins. ${ }^{7}$ Two strong clusters are observed corresponding to $\phi=-60^{\circ}, \psi=-30^{\circ}$ and $\phi=-60^{\circ}$, 
$\psi=+120^{\circ}$, which are the values required at the $i+1$ position of type I and II $\beta$-turns, respectively. We may therefore draw the inference that the enantiomeric residue ${ }^{\mathrm{D}}$ Pro will favour conformations which correspond to the $i+1$ position in type $\mathrm{I}^{\prime}$ and $\mathrm{II}^{\prime} \beta$-turns. The use of ${ }^{\mathrm{D}}$ Pro-Xxx segments to nucleate $\beta$-hairpin structures in peptides was developed at Bangalore $^{1}$ and independently in the group of Sam Gellman at Madison. ${ }^{42}$ Spectroscopic investigation of the octapeptide Boc-Leu-Val-Val- ${ }^{\mathrm{D}}$ Pro-Gly-Leu-Val-Val-OMe first

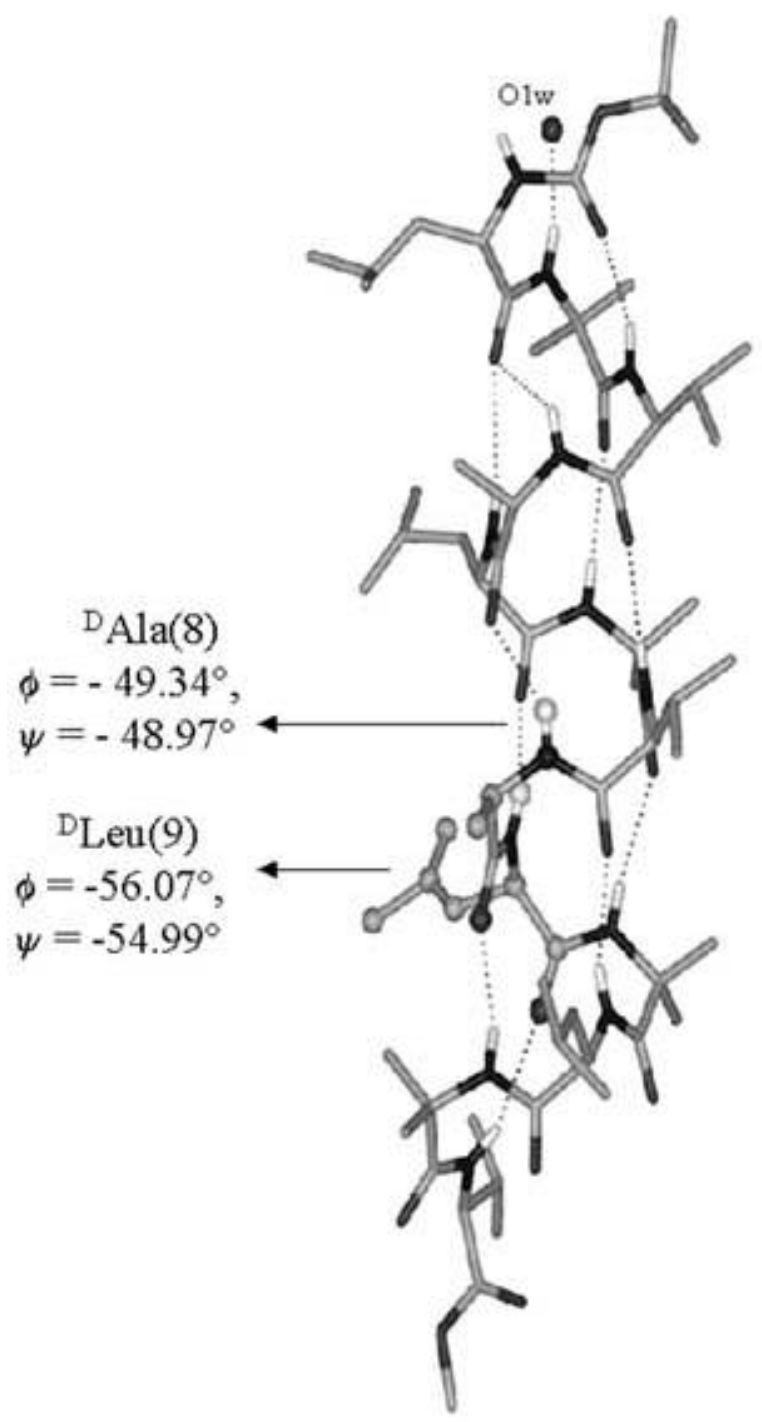

LUV13

Figure 10. Molecular conformation in crystals of a 13-residue peptide helix BocLeu-Aib-Val-Ala-Leu-Aib-Val- ${ }^{\mathrm{D}}$ Ala- ${ }^{\mathrm{D}}$ Leu-Aib-Leu-Aib-Val-OMe (LUV13, ref. 39) containing a centrally positioned ${ }^{\mathrm{D}} \mathrm{Ala}(8)-{ }^{\mathrm{D}} \mathrm{Leu}(9)$ double D-segment. 

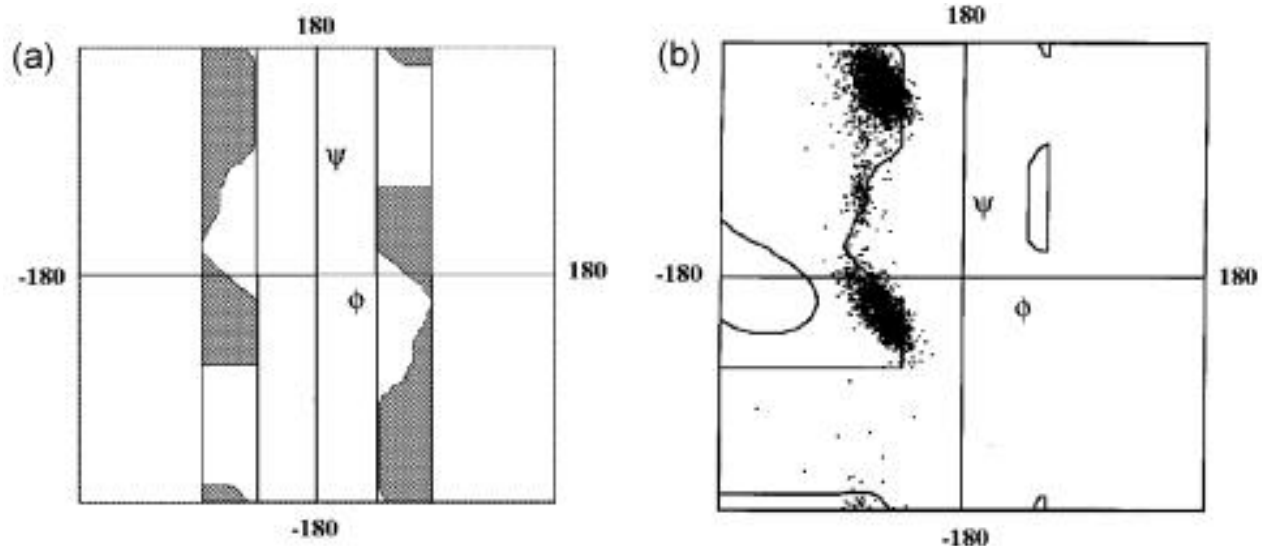

Figure 11. (a) The allowed regions in Ramachandran space for ${ }^{\mathrm{L}}$ Pro and ${ }^{\mathrm{D}}$ Pro residues (ref. 2). Note that the torsion angle $\phi$ is restricted to a relatively narrow range of $\phi$ values. ${ }^{\mathrm{L}}$ Pro $=-60 \pm 20^{\circ}$; ${ }^{\mathrm{D}}$ Pro $=+60 \pm 20^{\circ}$. (b) Observed distribution of conformational angles for 4995 Pro residues in 538 protein crystal structures (ref. $7 \mathrm{~b}$ ).

(a)

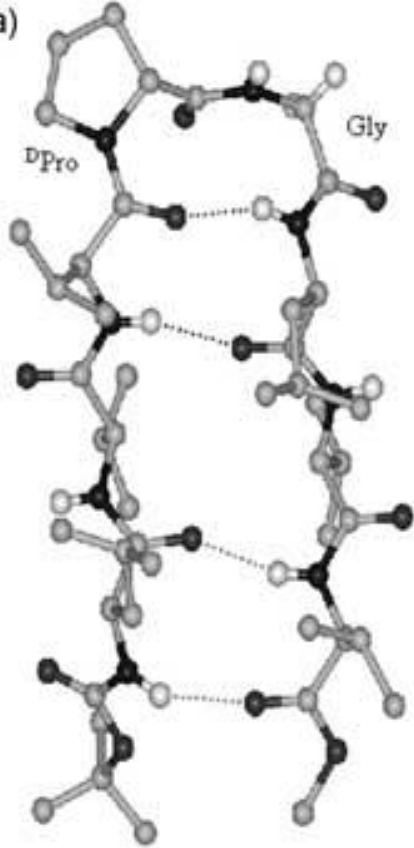

(b)

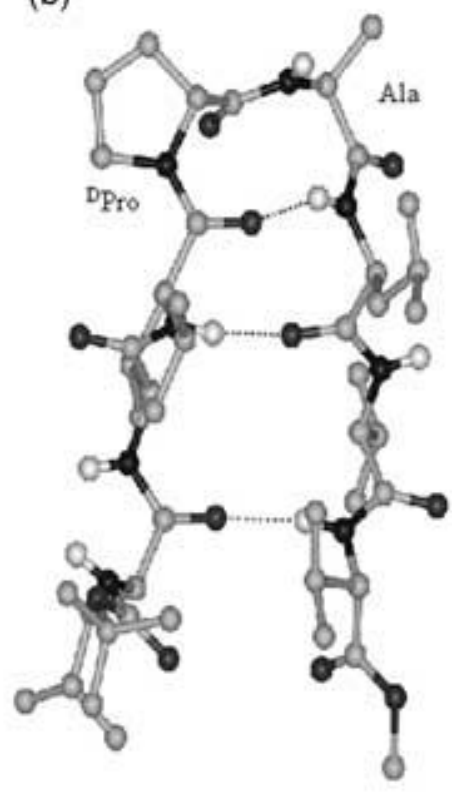

Figure 12. Molecular conformation in crystals observed for two synthetic octapeptides (a) Boc-Leu-Val-Val- ${ }^{\text {P}}$ Pro-Gly-Leu-Val-Val-OMe (ref. 44). (b) BocLeu-Val-Val- ${ }^{\mathrm{D}}$ Pro-Ala-Leu-Val-Val-OMe (ref. 45), Note there are two independent molecules in the asymmetric unit, having similar conformations; only one is shown. 


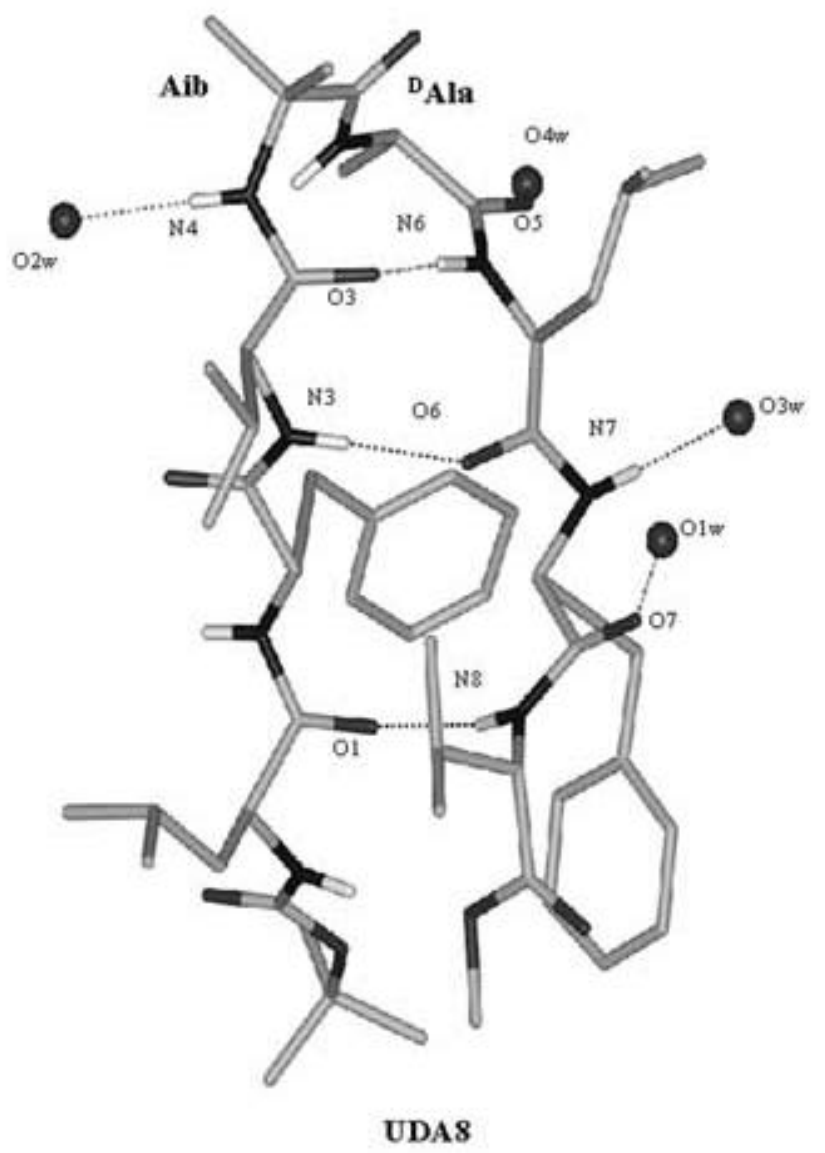

Figure 13. Molecular conformation in crystals observed for the octapeptide BocLeu-Phe-Val-Aib- ${ }^{\mathrm{D}}$ Ala-Leu-Phe-Val-OMe (UDA8, ref. 49). The Aib- ${ }^{\mathrm{D}}$ Ala segment forms a type $\mathrm{I}^{\prime} \beta$-turn.

revealed the formation of a stable hairpin in solution, as evidenced by the observation of all diagnostic interstrand nuclear Overhauser effects (NOEs). ${ }^{43}$ The subsequent crystal structure determination revealed two independent molecules in the crystallographic asymmetric unit, both of which adopted a $\beta$ hairpin conformation with the ${ }^{\mathrm{D}}$ Pro-Gly segment forming a type $\mathrm{II}^{\prime} \beta$ turn. ${ }^{44}$ Figure 12 illustrates the molecular conformation in crystals, determined by X-ray diffraction, for the two octapeptides Boc-Leu-Val-Val-

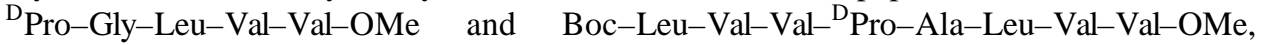
which contain centrally positioned, turn nucleating ${ }^{\mathrm{D}}$ Pro-Xxx segments. ${ }^{45} \beta$ hairpins have also been demonstrated in crystals for peptides Boc-Leu-Val-Val- ${ }^{\mathrm{D}}$ Pro-Gly-Leu-PheVal-OMe, Boc-Leu-Phe-Val- ${ }^{\mathrm{D}}$ Pro-Ala-Leu-Phe-Val-OMe, Boc-Met-Leu-Phe-Val${ }^{\mathrm{D}}$ Pro-Ala-Leu-Val-Val-Phe-OMe, Boc-Leu-Val-Val- ${ }^{\mathrm{D}}$ Pro-Aib-Leu-Val-Val-OMe, Boc-Leu-Phe-Val- ${ }^{\mathrm{D}}$ Pro-Ac ${ }_{8} \mathrm{c}-\mathrm{Leu}-\mathrm{Phe}-\mathrm{Val}-\mathrm{OMe}$. In all cases, the central ${ }^{\mathrm{D}}$ Pro-Xxx segment adopts type $\mathrm{II}^{\prime}$ turn conformations (unpublished). These crystallographic investigations establish the simple principle of nucleating stable hairpins by inserting 
${ }^{\mathrm{D}}$ Pro-Xxx segments into L-amino acid sequences. The extension of this approach to the design of three-, four- and five-stranded $\beta$-sheet structures has been achieved by the insertion of multiple ${ }^{\mathrm{D}}$ Pro-Xxx segments into designed peptide chains. Thus far, the characterisation of multi stranded $\beta$-sheets has been achieved in solution by twodimensional NMR methods. ${ }^{1,46}$ The largest sheet like structure achieved by synthetic design has been an eight stranded $\beta$-sheet in a 70 residue $C_{2}$ symmetric polypeptide, stabilised by a single disulfide bond. ${ }^{47}$ The search for alternative hairpin nucleating segments has encompassed both protein and non-protein amino acids. Asn-Gly sequences have been successfully employed in generating single $\beta$ hairpins and three stranded $\beta$-sheet structures characterised by NMR spectroscopy in solution. ${ }^{48}$ We have explored the possibility of using Aib- ${ }^{D}$ Xxx sequences to nucleate type I' $\beta$-turns ( $3_{10}$ helical turns). Figure 13 shows the molecular conformations in crystals of a designed octapeptide BocLeu-Phe-Val-Aib- ${ }^{\mathrm{D}}$ Ala-Leu-Phe-Val-OMe, which reveals a $\beta$ hairpin conformation nucleated by an Aib- ${ }^{\mathrm{D}}$ Ala type $\mathrm{I}^{\prime} \boldsymbol{\beta}$-turn. In this structure, cross-strand aromatic interactions between the Phe residues at position 2 and 7 (centroid to centroid distance for aromatic rings is $5 \cdot 52 \AA$ ) may lend further stability to the observed structure. Several recent investigations address the issue of stabilising $\beta$-hairpin conformations by specific cross-strand interactions between aromatic side chains. This approach is of particular relevance in the design of stable sheet like structures in water where hydrophobic clustering of side chains may lend additional stability to the design of backbone folds. ${ }^{50}$

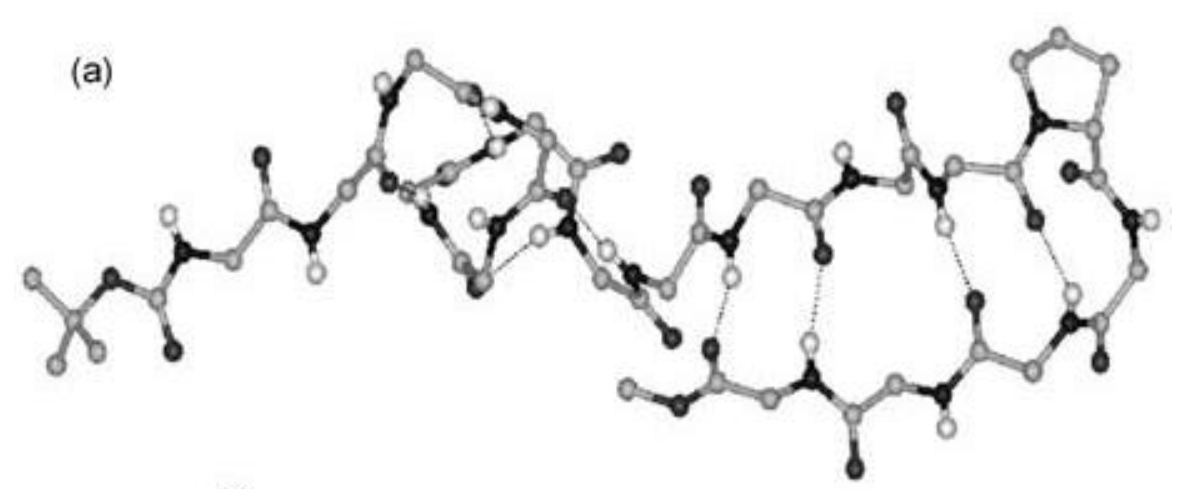

(b)

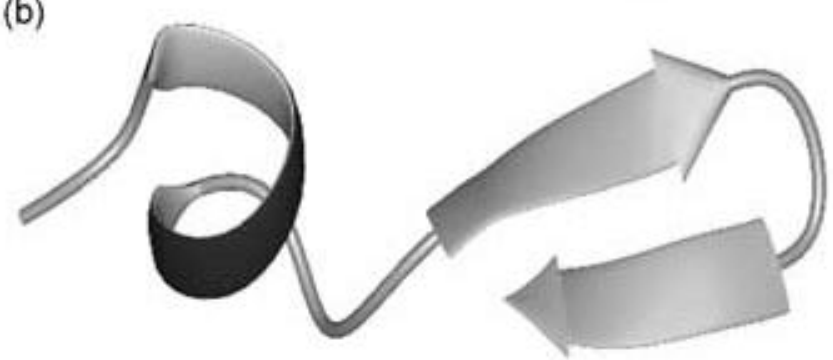

Figure 14. Molecular conformation in crystals for the synthetic 17-residue peptide Boc-Val-Ala-Leu-Aib-Val-Ala-Leu-Gly-Gly-Leu-Phe-Val- ${ }^{D}$ Pro-Gly-Leu-Phe$\mathrm{Val}-\mathrm{OMe}$ (ref. 52). (a) Note the two distinct secondary structure segments residues 1-7 form a helix, while residues 10-17 form a hairpin. (b) Ribbon representation illustrating the orientation of the two secondary structures. 

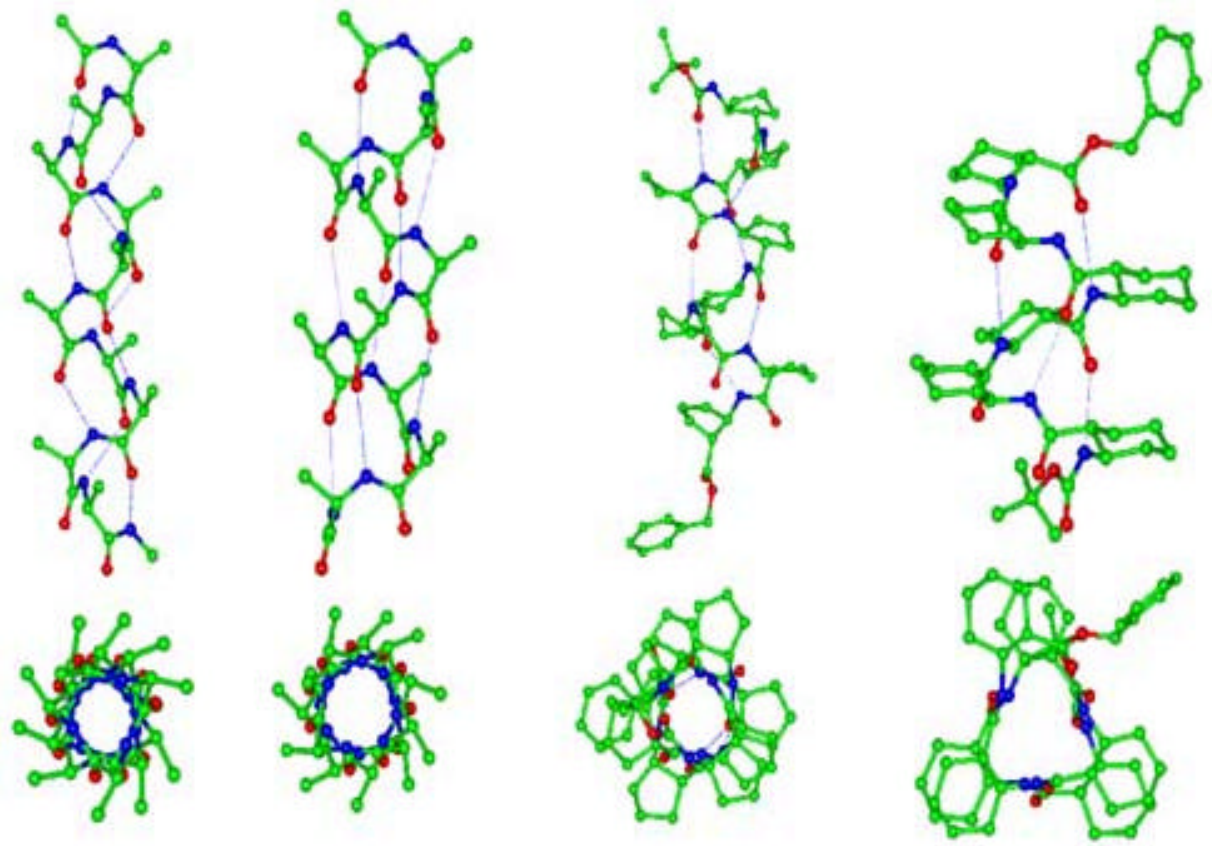

a

c

d

Figure 15. A comparison of the helical structures formed by poly $\alpha$-peptides and poly $\beta$-peptides. (a) and (b) correspond to the $3_{10}$ and $\alpha$-helical structures observed in polypeptides formed by $\alpha$-amino acids. (c) 12-helix formed in the crystal structure of an oligomer of the $\beta$-amino acid ACPC (ref. 59). (d) 14-helix formed in the crystal structure of an oligomer of the $\beta$-amino acid ACHC (ref. 60). A view perpendicular to the helix axis is shown on top. The lower figures are a view down the helix axis.

\section{Mixed $\boldsymbol{\alpha} / \boldsymbol{\beta}$ structures}

Well-defined modules of secondary structure $(\alpha$ and $\beta$ ) have been combined in synthetic peptides to yield mixed $\alpha \beta$ structures. The existence of distinct helix and hairpin segments have been demonstrated in the 17 residue sequence, Boc-Leu-Aib-Val-Ala-Leu-

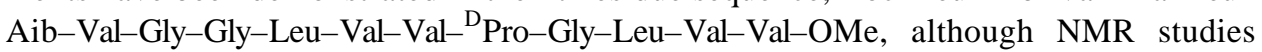
were unable to clearly define the relative orientation of the two modules. ${ }^{51}$ The related 17 residue peptide, Boc-Val-Ala-Leu-Aib-Val-Ala-Leu-Gly-Gly-Leu-Phe-Val- ${ }^{\text {D}}$ ProGly-Leu-Phe-Val-OMe, yielded single crystals permitting X-ray diffraction studies, which established a right-handed helical segment spanning residues 1 to 7 , terminating in a Schellman motif with residue 8 at position T. The segment $10-17$ forms a $\beta$-hairpin nucleated by a type II $^{\prime} \beta$-turn, with ${ }^{\mathrm{D}}$ Pro-Gly as the corner residues (figure 14). ${ }^{52}$ Building in greater $\phi \psi$ restrictions at the linking segments between secondary structures may permit greater control on the orientation of the helix and strand modules.

\section{9. $\beta$ - and $\boldsymbol{\gamma}$-amino acid residues in peptides}

The stereochemistry of peptides and polypeptides containing omega amino acids has been reviewed, with specific attention to early studies on homopolymers. ${ }^{53}$ In $\beta$-amino 


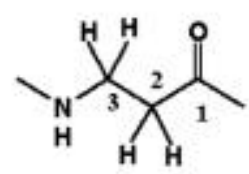

p<smiles>[R]C([R])(C(C)=O)C([2H])NC</smiles>

$\beta^{2}=$<smiles>[R]C([R])(NC)C([R])([R])C(C)=O</smiles>

$\beta^{2,2,3,3}$<smiles>[2H]C([2H])(NC)C(C)=O</smiles>

$\beta^{3}$<smiles>[R]C([2H])(NC)C(C)=O</smiles>

ps?

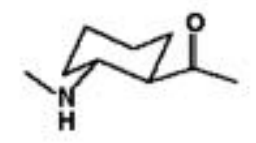

ACHC<smiles>[R]C([2H])([2H])C(C)NC</smiles>

$\rho$<smiles>[R]C([2H])(NC)C([2H])([2H])C(C)=O</smiles>

pe.1.3.<smiles>CNC1C=C(C)CCC1</smiles>

ACPC

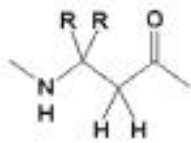

pes<smiles>[R]C([R])(NC)C([R])([R])C(C)=O</smiles>

p.2.3<smiles>CC(=O)C1CCCN(C)C1</smiles>

Nipecotic Acia

Figure 16. Nomenclature for $\beta$-residues.

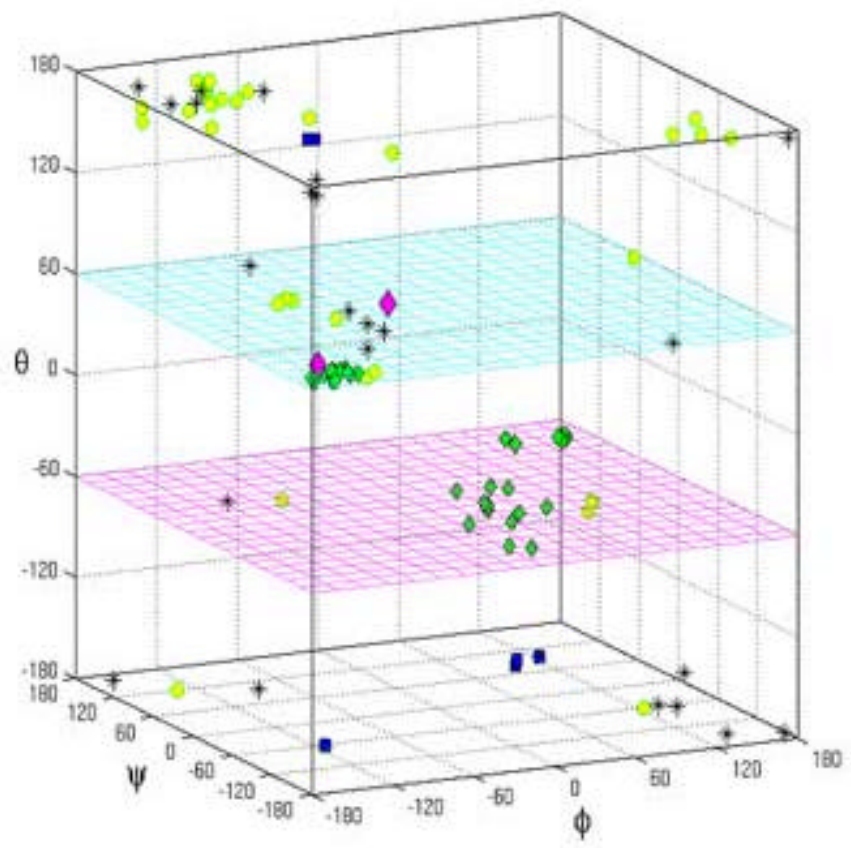<smiles>CNC(C)(C)CC(C)(C)C(C)=O</smiles>

Figure 17. Observed $\beta$-residue conformations in crystal structures of synthetic peptides representing on a three-dimensional $\phi-\theta-\psi$ plot. The coloured planes correspond to the gauche conformation about $\mathrm{C}^{\alpha}-\mathrm{C}^{\beta}$ bonds. * (black): achiral acyclic unsubstituted $\beta$-amino acid, $\beta$-glycine (3-amino propionic acid); o (yellow): acyclic substituted $\beta$-amino acids; $\diamond$ (green): chiral cyclic $\beta$-amino acids; (blue): nipecotic acid( pink): idealised 12 - and 14-helices. 


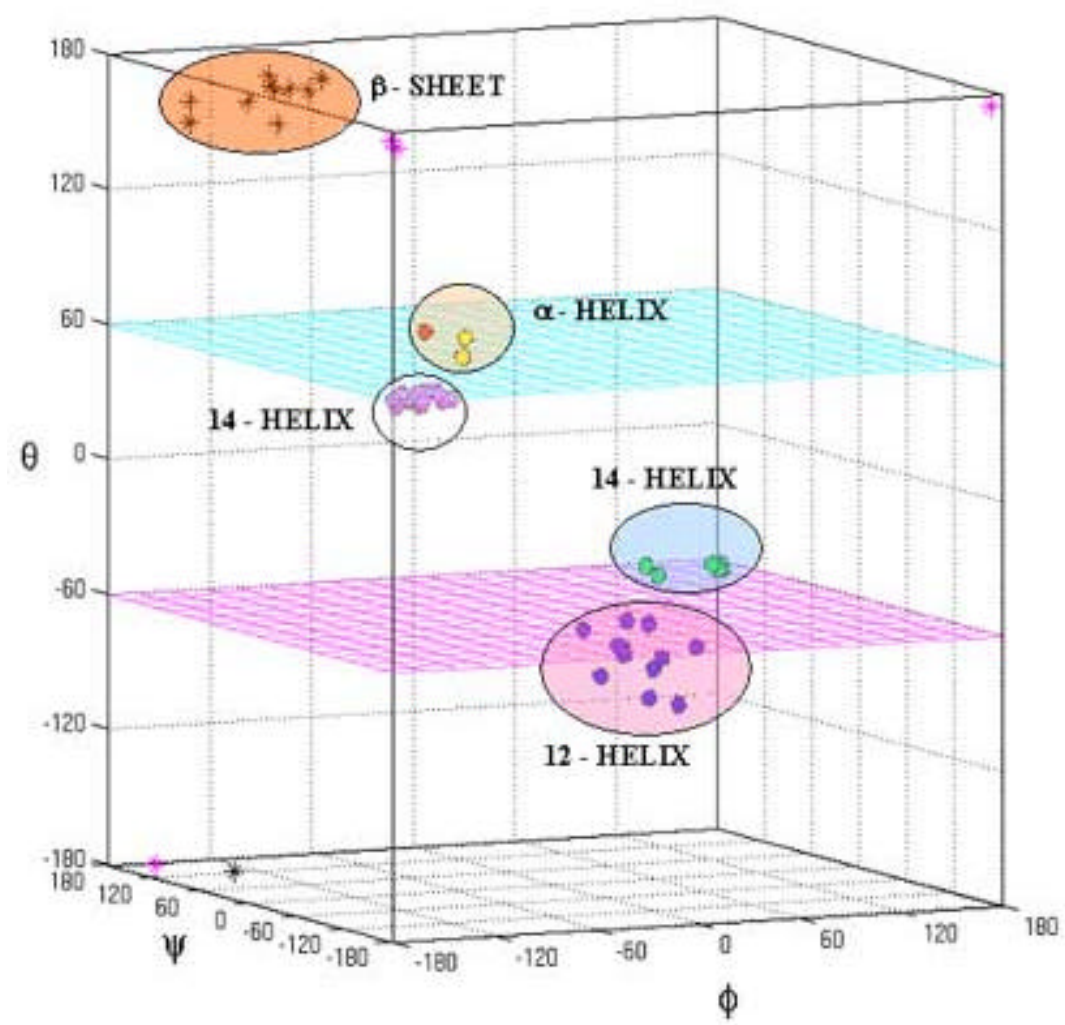

Figure 18. Location of the regions of ordered secondary structures for $\beta$-residues in $\phi-\theta-\psi$ space. The $\alpha$-helix and $\beta$-sheet are the classical structures for poly $\alpha$-amino acids. $\beta$-residues occurring in the appropriate shaded region can be accommodated without disruption of secondary structures. The 12-helix and 14-helix are well characterised secondary structures for poly $\beta$-peptides.

acid residues the introduction of an additional degree of torsional freedom $(\theta)$ into the backbone is expected to enhance conformational flexibility. Helical structures have been postulated for poly( $\alpha$ alkyl- $\beta$-aspartates) on the bases of fibre diffraction, polarised IR spectroscopy and molecular mechanics and quantum chemical calculations by MunozGuerra, Subirana, Alemann and coworkers. ${ }^{54}$ Interest in the conformations of $\beta$-peptides received a dramatic boost with the work of Dieter Seebach ${ }^{55}$ and Sam Gellman ${ }^{56}$ which established, unequivocally, the ability of oligopeptides containing $\beta$ residues to fold into helical conformations, which are completely distinct from those adopted by ofpeptides. Figure 15 illustrates the well characterised helical forms observed in poly $\alpha$ and poly $\beta$ peptides. The flood of recent research in the area of $\beta$ and $\gamma$ peptides has been facilitated by the synthetic accessibility of many chiral, multiply substituted $\beta$ and $\gamma$ residues. ${ }^{57}$ Figure 16 defines the general formulae for $\beta$-amino acids and the nomenclature used for representing substituted residues. The structures of three cyclic $\beta$-amino acids in which rotation about the central $C^{\alpha}-C^{\beta}$ bond $(\theta)$ is restricted are also shown. The formation of folded structures in $\beta$-peptides immediately suggests that these residues may be used to expand the range of designed peptide conformations, particularly when used in conjunction with stereochemically constrained residues. 


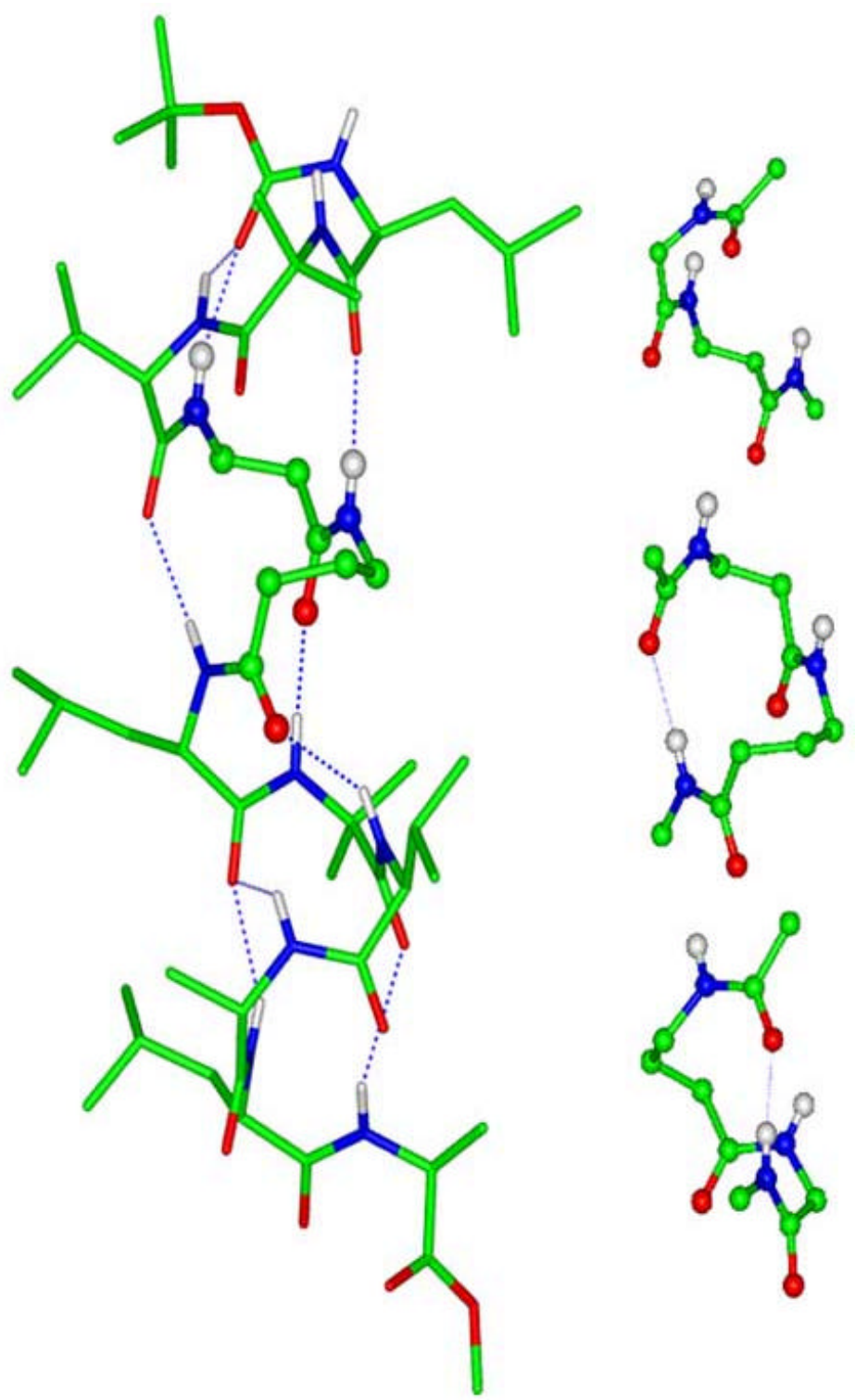

Figure 19. Molecular conformation in crystals for the 11 residue synthetic peptide Boc-Leu-Aib-Val- $\beta$-Gly- $\gamma$-Abu-Leu-Aib-Val-Ala-Leu-Aib-OMe (ref. 61) accommodating a central $\beta$-Gly- $\gamma-$ Abu segment. The dipeptide segments are shown on the right. (top) Val- $\beta-$ Gly, (middle) $\beta$-Gly- $\gamma-$ Abu and (bottom) $\gamma-\mathrm{Abu}-\mathrm{Leu}$.

The rational use of $\beta$-residues in peptide design requires an understanding of the nature of the local conformations, which are readily accessible. Conformational space for $\beta$-residues can be conveniently represented in a three dimensional $\phi-\theta-\psi$ plot, in a simple extension of the Ramachandran analysis for $\alpha$-residues. ${ }^{58}$ Figure 17 shows the observed distribution of $\phi \theta, \psi$ values for $\beta$-residues in peptide crystal structures. Both $\beta$ 
oligopeptides and hybrid $\alpha \beta$-sequences are included. The conformation about the central $\mathrm{C}-\mathrm{C}$ bond is overwhelmingly restricted to the anticipated gauche $^{+}\left(\mathrm{g}^{+}, \boldsymbol{\theta}=+60^{\circ}\right)$ gauche $^{-}$ $\left(g^{-}, \boldsymbol{\theta}=-60^{\circ}\right)$ and trans $\left(t, \boldsymbol{\theta}=180^{\circ}\right)$ conformations. The $g^{+}$and $g^{-}$conformations induce helical folding. Figure 18 illustrates the observed clusters in conformational space for $\beta$-residues incorporated into regular secondary structures. The 12-helix and 14-helix have been crystallographically characterised in oligomers of the constrained $\beta$-amino acid $\mathrm{ACPC}^{59}$ and $\mathrm{ACHC}^{60}$ (see also figure 15). $\beta$ residues can be incorporated into $\alpha$ helical and $\beta$-sheet structures formed by predominately $\alpha$ amino acid sequences. We have undertaken a systematic characterisation of the conformational characteristics of hybrid peptides containing $\boldsymbol{\alpha}, \boldsymbol{\beta}$, and $\gamma$ residues.

The crystal structures of the peptides Boc-Leu-Aib-Val- $\beta-$ Gly- $\boldsymbol{\gamma}-\mathrm{Abu}-\mathrm{Leu}-\mathrm{Aib}-$ $\mathrm{Val}-\mathrm{OMe}$ and Boc-Leu-Aib-Val- $\boldsymbol{\beta}-$ Gly- $\boldsymbol{\gamma}$-Abu-Leu-Aib-Val-Ala-Leu-Aib-OMe provided the first examples of the incorporation of the $\beta \gamma$ segment into helical $\alpha$-peptide structures. $^{61}$ (In the original report ${ }^{61}$ the $\beta$-Gly residue was called $\beta$-Ala, which has been the trivial name used for 3-aminopropionic acid. Following the growth of the literature on $\beta$-residues and $\beta$-peptides, the designation $\beta$-Ala is best reserved for the $\beta$-residue obtained by backbone homologation of the residue Ala). Figure 19 shows the structure of
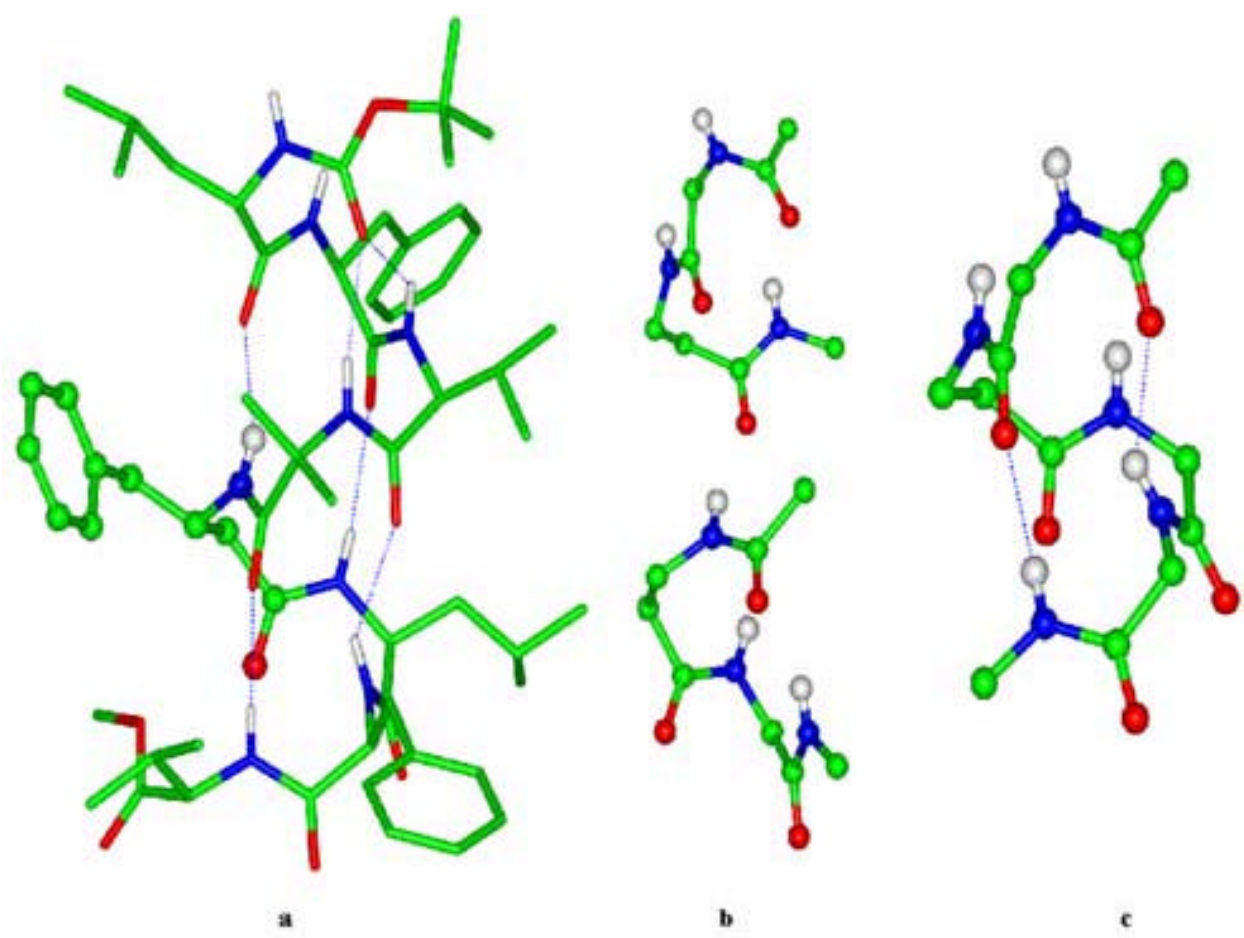

Figure 20. (a) Molecular conformation in crystals of the helical octapeptide BocLeu-Phe-Val-Aib- $\beta$-Phe-Leu-Phe-Val-OMe, which incorporates a single $\beta$-Phe residue. (b) View of the dipeptide segments Aib- $\beta$-Phe (top) and $\beta$-Phe-Leu (bottom). In both cases the $\mathrm{N} \cdots \mathrm{O}$ distance corresponding to a potential hydrogen bond are outside the normal limits. (c) An expanded view of Aib- $\beta-P h e-L e u$ segment. Two $\mathrm{C}_{14}$ hydrogen bonds are observed, corresponding to the expansion of the $\alpha$-helical turn by insertion of an additional carbon atom into the peptide backbone. 


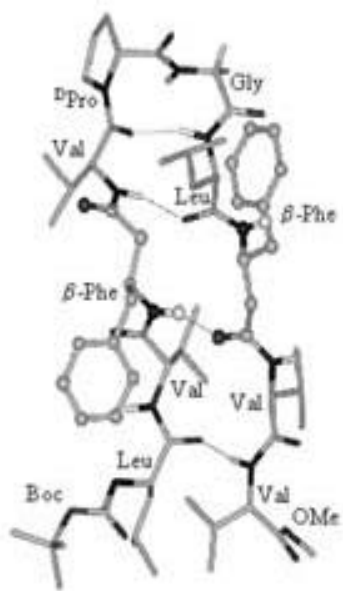

(a)

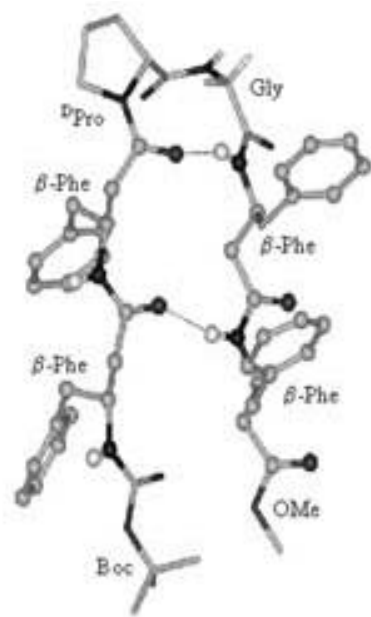

(b)

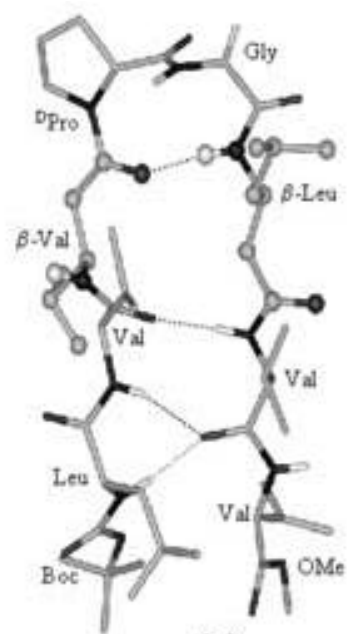

(c)

Figure 21. Molecular conformation observed in crystals for peptides containing $\beta$-residues in the strand segments of $\beta$-hairpins (a) Boc-Leu-Val- $\beta-P h e-V a-{ }^{D}$ ProGly-Leu- $\beta-$ Phe-Val-Val-OMe, ( ${ }^{D}$ Pro-Gly: type I' $\beta$-turn) (ref. 62), (b) Boc- $\beta$-Phe-

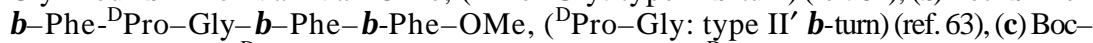
Leu-Val- $\beta-$ Val- ${ }^{\mathrm{D}}$ Pro-Gly- $\beta$-Leu-Val-Val-OMe ( ${ }^{\mathrm{D}}$ Pro-Gly: type I' $\beta$-turn) (ref. 58).

the 11 residue helix, incorporating a central $\beta$ Gly- $\gamma$ Abu segment. Helical folding of the host sequence is facilitated by the introduction of Aib residues at positions 2, 7 and 11 . The insertion of three additional $\mathrm{CH}_{2}$ groups into the helix backbone does not have a major disrupting influence on the structure. Figure 19 also shows a view of the three dipeptide segments Val- $\beta-$ Gly $(\alpha \beta), \beta-G l y-\gamma \mathrm{Abu}(\beta \gamma)$ and $\gamma \mathrm{Abu}-\mathrm{Val}(\gamma \propto)$ ). Internal $4 \rightarrow 1$ hydrogen bonds are observed in the $\beta \gamma\left(13\right.$ atom hydrogen bonded ring, $\left.C_{13}\right)$ and $\gamma \alpha\left(12\right.$ atom hydrogen bonded ring, $\mathrm{C}_{12}$ ) segments. The backbone torsion angles at the $\beta \gamma$ segments are $\beta$ Gly: $\phi=-103^{\circ}, \theta_{1}=78^{\circ}$ and $\psi=-107^{\circ} . \gamma \mathrm{Abu}: \phi=-121^{\circ}, \theta_{1}=57^{\circ}, \theta_{2}=$ 62 and $\psi=-121^{\circ}$. In the eight residue peptide the corresponding values are $\beta$ Gly: $\phi=$ $-130^{\circ}, \theta_{1}=76^{\circ}$ and $\psi=-162^{\circ} . \gamma \mathrm{Abu}: \phi=-108^{\circ}, \theta_{1}=58^{\circ}, \theta_{2}=66^{\circ}$ and $\psi=-169^{\circ}$. Accommodation of $\beta$ and $\gamma$ residues into helical folds is achieved by adoption of gauche $e^{+}\left(g^{+}\right)$conformations at the additional $\mathrm{C}-\mathrm{C}$ bond. An example of the insertion of a single $\beta$-residue into an $\alpha$ peptide helix is observed in the structure of the octapeptide

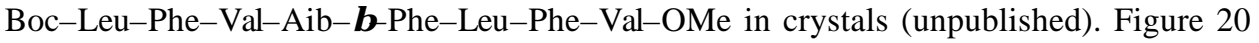
shows a view of the molecular conformation. An expanded view of the oßoxsegment is also shown. The dipeptide segments Aib- $\beta$-Phe $(\alpha \beta)$ and $\beta$-Phe-Val $(\beta O \alpha)$ do not form strong $4 \rightarrow 1$ hydrogen bonds, which would result in 11 atom rings. Instead hydrogen bonds of the $5 \rightarrow 1$ type, which result in a 14 atom hydrogen bonded ring are observed in the $\alpha \beta \alpha$ and $\beta$ oo $\alpha$ segments. The observed conformational angles for the guest $\beta$-Phe residue in the host $\alpha$-peptide helix are $\phi=-122 \cdot 4^{\circ}, \theta_{1}=1.3^{\circ}$ and $\psi=-98 \cdot 7^{\circ}$.

While relatively few examples exist of the insertion of $\beta$ and $\gamma$ residues into $\alpha$ peptide helices, incorporation into strand segments of hairpins is readily achieved. Several crystalline peptide hairpins, nucleated by ${ }^{\mathrm{D}}$ Pro-Gly turning segments, containing 
$\beta$-residue in the strands have been crystallographically characterized. ${ }^{58,62,63}$ Figure 21 shows three representative $\beta$-hairpin structures containing $\beta$-residues. The insertion of $\beta$ Phe residues in the strand segment results in a change of the polarity of the strand, as compared to the strands containing $\alpha$-residues. In the case of $\beta$-peptide strands, adjacent carbonyl groups point in one direction, while the $\mathrm{NH}$ groups are oriented in the opposite direction, leading to the formation of polar sheets in crystals. In most of the observed structures, the $\beta$-residues used have been $\beta$-Phe, $\beta$-Val and $\beta$-Leu, with average torsion angles of $\phi=-113 \pm 20^{\circ}, \boldsymbol{\theta}=163 \pm 7^{\circ}$ and $\boldsymbol{\psi}=127 \pm 19^{\circ}$ (values averaged over $10 \beta$ residues). An interesting distortion is observed in the crystal structure of the octapeptide Boc-Leu-Val- $\boldsymbol{\beta}-$ Val- ${ }^{\text {D }}$ Pro-Gly- $\boldsymbol{\beta}-$ Leu-Val-Val-OMe (figure 21 ). While the hairpin nucleated by a type $I^{\prime}$ Dro-Gly $\beta$-turn is clearly observed, the $\beta$-Val(3) residue adopts a

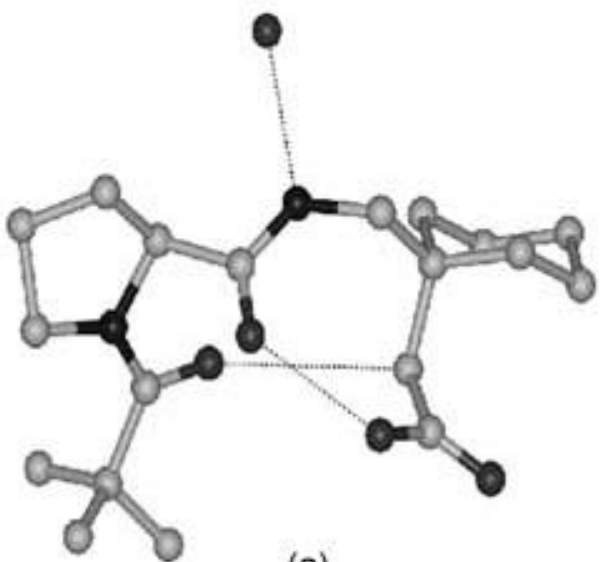

(a)

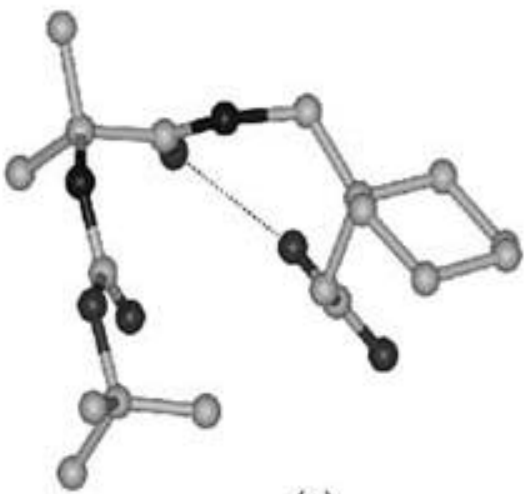

(c)
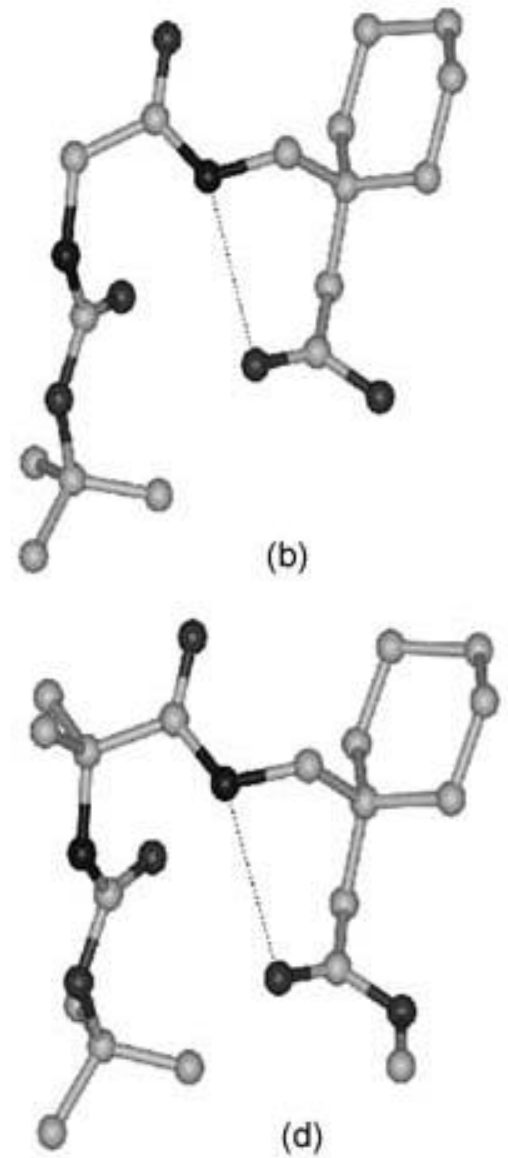

Figure 22. Molecular conformations in crystals in four peptides containing the constrained $\gamma$-amino acid residue gabapentin (Gpn). (a) Piv-Pro-Gpn-OH; Gpn $\phi=92.9^{\circ}, \theta_{1}=-66.7^{\circ}, \theta_{2}=-70.7^{\circ}$ and $\psi=84.6^{\circ}$ (b) Boc-Gly-Gpn-OH; Gpn $\phi=$ $-103.7^{\circ}, \theta_{1}=-44.9^{\circ}, \theta_{2}=-48.7^{\circ}$ and $\psi=-94.3^{\circ}$ (c) Boc-Aib-Gpn-OH; Gpn $\phi=103.9^{\circ}, \theta_{1}=-57.3^{\circ}, \theta_{2}=-75.5^{\circ}$ and $\psi=-73.5^{\circ}$ (d) Boc-Aib-Gpn-OMe; Gpn $\phi=$ $-102 \cdot 1^{\circ}, \theta_{1}=-48 \cdot 2^{\circ}, \theta_{2}=-50 \cdot 3^{\circ}$ and $\psi=-90 \cdot 0$ (ref. 65). 
gauche $e^{+}$conformation $\phi=-131^{\circ}, \theta=65^{\circ}$ and $\psi=-175^{\circ}$. Despite the $g^{+}$conformation about the $C^{\alpha}-C^{\beta}$ bond in $\beta \operatorname{Val}(3)$, cross hydrogen bonding is not disturbed with a compensating distortion at $\beta$-Val resulting in an almost completely extended value $\left(-175^{\circ}\right)$ for $\psi .^{58}$

$\beta$-residues can also be accommodated in the turn segments of hairpins although no crystal structures have yet been determined for large hairpins. The dinipecotic acid segment has been shown to induce hairpin formation in short tetrapeptide sequences. ${ }^{64}$ NMR studies in solution provide evidence for the accommodation of $\beta$-Phe at the $i+2$ position of the turn segment in the synthetic peptide Boc-Leu-Val-Val- ${ }^{\mathrm{D}}$ Pro- $\beta-\mathrm{Phe}-$ Leu-Val-Val-OMe. ${ }^{58}$ In recent work, we have began exploring the use of the stereochemically constrained, achiral $\beta \beta$-disubstituted $\gamma$ amino acid, gabapentin (1-(aminomethyl) cyclohexaneacetic acid, Gpn) into short $\alpha$ amino acid containing peptides. The presence of the geminal substituents at the central atom restrict the torsion angles $\boldsymbol{\theta}_{1}$ and $\theta_{2}$ to $\pm 60^{\circ}$, resulting in obligatory folding of the chain upon insertion of the Gpn residue. Figure 22 shows the molecular conformation of four model peptides containing the Gpn residue. $^{65}$ In each case, the local folding of the chain is clearly evident with gauche conformations observed about the $C^{\alpha}-C^{\beta}\left(\boldsymbol{\theta}_{1}\right)$ and $C^{\beta}-C^{\gamma}\left(\boldsymbol{\theta}_{2}\right)$ bonds. Interestingly, the unsubstituted $\delta$ amino acid, $\delta$ aminovaleric acid ( $\boldsymbol{\delta} \mathrm{Ava}$ ) can be incorporated into designed $\propto$ amino acid structures. The insertion of $\delta$ Ava at the $i+2$ position of the turn segment of a $\beta$-hairpin ${ }^{66}$ and into the centre of a peptide helix ${ }^{67}$ have been established by NMR studies of model peptides in solutions.

The incorporation of $\beta$ and $\gamma$ amino acids into hybrid peptide sequences can impart proteolytic stability to biologically active peptides. ${ }^{68}$ It will be interest to design pharmacologically important peptides, to specially inhibit proteolysis at labile sites by backbone modification. In such cases the analog peptides must largely retain the conformation of the parent sequence in order to manifest biological activity. The exploration of the effect of $\beta$ and $\gamma$-residues on the conformation of host $\alpha$ peptides may provide a rational basis for the choice of sites for insertion.

\section{Conclusion}

The use of stereochemically constrained amino acid residues can limit the range of local conformations of polypeptide chains, thereby nucleating folding and formation of defined secondary structures. This review has focused primarily on the role of $\alpha$ aminoisobutyric acid (Aib) in promoting helix formation, D-amino acid residues in facilitating helix termination and ${ }^{\mathrm{D}}$ Pro-Xxx segments in nucleating $\beta$ hairpin structures. The work reviewed has been largely based on the crystallographic characterisation of peptide conformations in the solid state, in the case of helices and hairpins. For multi-stranded $\beta$-sheets, which have thus far not yielded single crystals, two-dimensional NMR spectroscopy has provided firm evidence for the nature of the designed structures in solution. The use of $\beta$ and $\gamma$ amino acids offers the possibility of extending the range of well defined peptide structures, beyond those normally observed in natural proteins. The availability of structurally well characterised peptide modules has facilitated investigation of side chain interactions, notably between aromatic groups ${ }^{69}$ and permitted mechanistic investigations of proximity effects in catalysis of biologically relevant reactions, like the Amadori rearrangement of glycated peptides. ${ }^{70}$ Furthermore, structurally rigid peptide scaffolds have provided the bases for the design of new catalytically active sequences. $^{71}$ 


\section{Acknowledgements}

PB thanks Isabella Karle, Naval Research Laboratory, Washington DC, for a long and fruitful collaboration on the structural analysis of peptides and her many insights into peptide folding. We are grateful to B S Sanjeev for help in generating figures 17, 18 and Anindita Sengupta and K Muruga Poopathi Raja for the details of figure 20. Research in this area at Bangalore has been supported by grants from the Department of Science and Technology, Council of Scientific and Industrial Research (NS) and Program Support from the Department of Biotechnology, Government of India.

\section{Reference}

1. Kaul R and Balaram P 1999 Bioorg. Med. Chem. 7105

2. Venkatraman J, Shankaramma S C and Balaram P 2001 Chem. Rev. 1013131

3. Ramachandran G N, Ramakrishnan C and Sasisekharan V 1963 J. Mol. Biol. 795

4. (a) Pauling L, Corey R B and Branson H R 1951 Proc. Natl. Acad. Sci. USA 37 205; (b) Pauling L and Corey R B 1951 Proc. Natl. Acad. Sci. USA 37251

5. Ramakrishnan C and Ramachandran G N 1965 Biophys. J. 5909

6. Ramachandran G N and Sasisekharan V 1968 Adv. Prot. Chem. 23284

7. (a) Ramakrishnan C and Srinivasan N 1990 Curr. Sci. 59 851; (b) Gunasekaran K 1997 Stereochemical analysis of protein structures-lessons for design, engineering and prediction, $\mathrm{Ph} \mathrm{D}$ thesis, Indian Institute of Science, Bangalore

8. Ramachandran G N and Chandrasekaran R 1972 In Progress in peptide research (ed.) S Lande (New York: Gordon and Breach) vol II, p 195 (Proceedings of the second American peptide symposium, Cleveland, 1970)

9. Marshall G R and Bosshard H E 1972 Circ. Res. 30/31 (suppl. II) 143

10. Burgess A W and Leach S J 1973 Biopolymers 122599

11. (a) Zhao M and Bada J L 1989 Nature (London) 339 463; (b) Ehrenfreund P and Charnley S B 2000 Annu. Rev. Astron. Astrophys. 38427

12. Peptaibol Database: http://public-1.cryst.bbk.ac.uk/peptaibol/home.shtml; (b) Chugh J K and W allace B A 2001 Biochem. Soc. Trans. 29565

13. (a) Pandey R C, Cook J C Jr and Rinehart K L Jr 1977 J. Am. Chem. Soc. 99 8469; (b) Fox R O Jr and Richards F M 1982 Nature (London) 300325

14. (a) Rinehart K L, Gaudioso L A, Moore M L, Pandey R C and Cook J C Jr 1981 J. Am. Chem. Soc. 103 6517; (b) Karle I L, Flippen-Anderson J L, Agarwalla S and Balaram P 1991 Proc. Natl. Acad. Sci. USA $\mathbf{8 8} 5307$

15. (a) Pandey R C, Cook J C Jr and Rinehart K L Jr 1977 J. Am. Chem. Soc. 99 5203; (b) Brückner H, Nicholson G J, Jung G, Kruse K and König WA 1980 Chromatographia 13 209

16. (a) Karle I L, Perozzo M A, Mishra V K and Balaram P 1998 Proc. Natl. Acad. Sci. USA 95 5501; (b) Snook C F, Woolley G A, Oliva G, Patthabi V, Wood S F, Blundell TL and Wallace B A 1998 Structure 6 783; (c) Snook C F and Wallace B A 1999 Acta Crystallogr. D55 1539

17. (a) Sansom M S P 1991 Prog. Biophys. Mol. Biol. 55 139; (b) Sansom M S P 1993 Q. Rev. Biophys. 26 365; (c) Tieleman D P, Biggin P C, Smith G R and Sansom M S P 2001 Q. Rev. Biophys. 34473

18. (a) Shamala N, Nagaraj R and Balaram P 1977 Biochem. Biophys. Res. Commun. 79 292; (b) Nagaraj R, Shamala N and Balaram P 1979 J. Am. Chem. Soc. 101 16; (c) Nagaraj R and Balaram P 1981 Acc. Chem. Res. 14356

19. Shamala N, Nagaraj R and Balaram P 1978 J. Chem. Soc. Chem. Commun. 996

20. (a) Smith G D, Pletnev V Z, Duax W L, Balasubramanian T M, Bosshard H E, Czerwinski E W, Kendrick N E, Mathews F S and Marshall G R 1981 J. Am. Chem. Soc. 103 1493; (b) Marshall G R, Hodgkin E E, Langs D A, Smith G D, Zabrocki J and Leplawy M T 1990 Proc. Natl. Acad. Sci. USA 87487

21. (a) Bruckner H, Konig W A, Greiner M and Jung G 1979 Angew. Chem., Int. Ed. Engl. 18 476; (b) Butters T, Hutter P, Jung G, Pauls P, Schmitt H, Sheldrick G M and Winter W 1981 
Angew. Chem., Int. Ed. Engl. 20 889; (c) Jung G, Bosch R, Katz E, Schmitt H, Voges K P and Winter W 1983 Biopolymers 22 241; (d) Jung G, Bruckner H, Bosch R, Winter W, Schaal H and Strahle J 1983 Liebigs. Ann. Chem. 1096; (e) Bosch R, Jung G and Winter W 1983 Acta Crystallogr. C39 776; (f) Bosch R, Schmitt H, Jung G and Winter W 1985 Biopolymers 24 961 (g) Bosch R, Jung G, Schmitt H and Winter W 1985 Biopolymers 24979

22. (a) Prasad B V V and Balaram P 1984 CRC Crit. Rev. Biochem. 16 307; (b) Toniolo C and Benedetti E 1988 ISI atlas of science: Biochemistry 1 225; (c) Karle I L and Balaram P 1990 Biochemistry 29 6747; (d) Toniolo C and Benedetti E 1991 Trends Biochem. Sci.16 350; (e) Karle I L 1992 Acta Crystallogr. B48 341; (f) Benedetti E 1996 Biopolymers (Peptide Science) 40 3; (g) Karle I L 1996 Biopolymers (Peptide Science) 40157

23. Toniolo C, Crisma M, Bonora G M, Benedetti E, Di Blasio B, Pavone V, Pedine C and Santini 1991 Biopolymers 31129

24. Karle I L, Flippen-Anderson J L, Sukumar M, Uma K and Balaram P 1988 Proc. Natl. Acad. Sci. USA 85299

25. Datta S 1998 Folding of the designed peptides: X-ray crystallographic studies on the structure, conformation, aggregation and interactions of oligopeptides containing conformationally constrained amino acids, $\mathrm{Ph} \mathrm{D}$ thesis, Indian Institute of Science, Bangalore

26. (a) Baker E N and Hubbard R E 1984 Prog. Biophys. Mol. Biol. 44 97; (b) Datta S, Shamala N, Banerjee A and Balaram P 1997 J. Peptide Res. 49604

27. (a) Karle I L, Flippen-Anderson J L, Gurunath R and Balaram P 1994 Protein Science 3 1547; (b) Millhauser G M 1995 Biochemistry 34 3873; (c) Mammi S, Rainaldi M, Bellanda M, Schievano E, Peggion E, Broxterman Q B, Formaggio F, Crisma M and Toniolo C $2000 \mathrm{~J}$. Am. Chem. Soc. 122 11735; (d) Silva R A G, Yasui S C, Kubelka J, Formaggio F, Toniolo C and Keiderling T 2002 Biopolymers $\mathbf{6 5} 229$

28. Otoda K, Kitagawa Y, Kimura S and Imanishi Y 1993 Biopolymers 331337

29. (a) Sudha T S, Vijaykumar E K S and Balaram P 1983 Int. J. Peptide Protein Res. 22 464; (b) Miick S M, Martinez G V, Fiori W R, Todd A P and Millhauser G L 1992 Nature (London) 359 653; (c) Basu G and Kuki A 1993 Biopolymers 33 995; (d) Toniolo C, Polese A, Formaggio F, Crisma M and Kamphius J 1996 J. Am. Chem. Soc. 1182744

30. (a) Schellman C 1980 In Protein folding (ed.) R Jaenicke (Amsterdam: Elsevier/North-Holland Biochemical Press) p. 53; (b) Milner-White E J 1988 J. Mol. Biol. 199 915; (c) Nagarajaram H A, Sowdhamini R, Ramakrishnan C and Balaram P 1993 FEBS Lett. 321 79; (d) Aurora R, Srinivasan R and Rose G D 1994 Science 264 1126; (e) Gunasekaran K, Nagarajaram HA, Ramakrishnan C and Balaram P 1998 J. Mol. Biol. 275917

31. For examples in designed peptides: (a) Karle I L, Flippen-Anderson J L, Uma Kand Balaram P 1993 Int. J. Peptide Protein Res. 42 401; (b) Di Blasio B, Pavone V, Saviano R, Fattorusso C, Pedone E, Benedetti E, Crisma M and Toniolo C 1994 Peptide Res. 7 55; (c) Banerjee A, Datta S, Pramanik A, Shamala N and Balaram P 1996 J. Am. Chem. Soc. 118 9477; (d) Datta S, Shamala N, Banerjee A, Pramanik A, Bhattacharjya S and Balaram P 1997 J. Am. Chem. Soc. 119 9246; (e) Datta S, Uma M V, Shamala N and Balaram P 1999 Biopolymers 5013

32. Aravinda S, Shamala N, Pramanik A, Das C and Balaram P 2000 Biochem. Biophys. Res. Commun. 273933.

33. Aravinda S, Shamala N, Bandyopadhyay A and Balaram P 2003 J.Am. Chem. Soc. (in press)

34. (a) Madan Babu M, Singh S K and Balaram P 2002 J. Mol. Biol. 322871 (b) Singh S K and Madan Babu M and Balaram P 2003 Proteins: Struct. Funct. Genet. 57167

35. Banerjee A, Raghothama S, Karle I L and Balaram P 1996 Biopolymers 39279

36. (a) Banerjee A 1996 Non-standard amino acids in peptide design, $\mathrm{Ph} \mathrm{D}$ thesis, Indian Institute of Science, Bangalore; (b) Karle I L 2001 Biopolymers (Peptide Science) 60351

37. Karle I L, Flippen-Anderson J L, Uma K and Balaram P 1990 Proteins: Struct. Funct. Genet. 7 62; Karle I L, Flippen-Anderson J L, Uma K and Balaram P 1993 Biopolymers 33827

38. Tang K, Green M M, Cheon K S, Selinger J V and Garetz B A 2003 J. Am. Chem. Soc. 125 7313

39. Aravinda S, Shamala N, Desiraju S and Balaram P 2002 Chem. Commun. 2454

40. (a) Sibanda B L and Thornton J M 1985 Nature (London) 316 170; (b) Wilmot C M and Thornton J M 1988 J. Mol. Biol. 203 211; (c) Sibanda B L, Blundell T L and Thornton J M 1989 J. Mol. Biol. 206758 
41. (a) Richardson J S 1981 Adv. Prot. Chem. 34 167; (b) Srinivasan N, Anuradha V S, Ramakrishnan C, Sowdhamini R and Balaram P 1994 Int. J. Pept. Prot. Res. 44112

42. (a) Haque T S, Little J C and Gellman S H 1996 J. Am. Chem. Soc. 118 6975; (b) Haque T S and Gellman S H 1997 J. Am. Chem. Soc. 119 2303; (c) Gellman S H 1998 Curr. Opin. Chem. Biol. 2 717; (d) Espinosa J F and Gellman S H 2000 Angew. Chem., Int. Ed. 392330

43. Awasthi S K, Raghothama S and Balaram P 1995 Biochem. Biophys. Res. Commun. 216 375

44. Karle I L, Awasthi S K and Balaram P 1996 Proc. Natl. Acad. Sci. USA 938189

45. Das C, Naganagowda G A, Karle I L and Balaram P 2001 Biopolymers 58335

46. (a) Balaram P 1999 J. Peptide. Res. 54 195; (b) Das C, Raghothama S and Balaram P 1998 J. Am. Chem. Soc. 120 5812; (c) Das C and Balaram P 1999 J. Chem. Soc., Chem. Commun. 967; (d) Venkatraman J, Naganagowda G A, Sudha R and Balaram P 2001 Chem. Commun. 2660

47. Venkatraman J, Naganagowda G A and Balaram P 2002 J. Am. Chem. Soc. 1244987

48. (a) de Alba E, Jimenez M A and Rico M 1997 J. Am. Chem. Soc. 119 175; (b) RamirezAlvarado M, Blanco F J and Serrano L 1996 Natl. Struct. Biol. 3 604; (c) Maynard A J and Searle M S 1997 J. Chem. Soc., Chem. Commun. 1297

49. Aravinda S, Shamala N, Rajkishore R, Gopi H N and Balaram P 2002 Angew. Chem., Int.Ed. 413863

50. (a) Tatko C D and Waters M L 2002 J. Am. Chem. Soc. 124 9372; (b) Waters ML2002Curr. Opin. Chem. Biol. 6736

51. Das C, Shankaramma S C and Balaram P 2001 Chem. Eur. J. 7840

52. Karle I L, Das C and Balaram P 2000 Proc. Natl. Acad. Sci. USA 973034

53. Banerjee A and Balaram P 1997 Curr. Sci. 731067

54. (a) Fernandez-Santin J M, Aymami J, Rodriguez-Galan A, Munoz-Guerra S and Subirana J A 1984 Nature (London) 311 53; (b) Bella J, Alemann C, Fernandez-Santin J M, Alegre C and Subirana J A 1992 Macromolecules 25 5225; (c) Navas J J, Alemann C, Lopez-Carrasquero F and Munoz-Guerra S 1995 Macromolecules 28 4487; (d) Lopez-Carrasquero F, Alemann C and Munoz-Guerra S 1995 Biopolymers 36 263; (e) Aleman C, Navas J J and Munoz-Guerra S 1997 Biopolymers 41721

55. (a) Seebach D and Matthews J L 1997 Chem. Commun. 2015; (b) Seebach D, Abele S, Gademann, Guichard G, Hintermann T, Jaun B, Matthews J L and Schreiber J 1998 Helv. Chim. Acta 81 932; (c) Seebach D, Abele S, Gademann K and Jaun B 1999 Angew. Chem., Int. Ed. 381595

56. (a) Gellman S H 1998 Acc. Chem. Res. 31 173; (b) Cheng R P, Gellman S H and DeGrado W F 2001 Chem. Rev. 1013219

57. Steer D L, Lew R A, Perlmutter P, Smith A I and Aguilar M I 2002 Curr. Med. Chem. 9 811

58. Gopi H N, Roy R S, Raghothama S, Karle I L and Balaram P 2002 Helv. Chim. Acta 85 3313

59. Appella D H, Christianson L A, Klein D A, Richards M R, Powell D R and Gellman S H 1999 J. Am. Chem. Soc. 1217574

60. Appella D H, Christianson L A, Karle I L, Powell D R and Gellman S H 1999 J. Am. Chem. Soc. 1216206

61. Karle I L, Pramanik A, Banerjee A, Bhattacharjya S and Balaram P 1997 J. Am. Chem. Soc. 1199087

62. Karle I L, Gopi H N and Balaram P 2001 Proc. Natl. Acad. Sci. USA 983716

63. Karle I L, Gopi H N and Balaram P 2002 Proc. Natl. Acad. Sci. USA 995160

64. (a) Chung Y J, Christianson L A, Stanger H E, Powell D R and Gellman S H 1998 J. Am. Chem. Soc. 120 10555; (b) Chung Y J, Huck B R, Christianson L A, Stanger HE, Krauthäuser S, Powell D R and Gellman S H 2000 J. Am. Chem. Soc. 1223995

65. Aravinda S, Ananda K, Shamala N and Balaram P 2003 Chem. Eur. J. 94789

66. Shankaramma S C, Singh S K, Sathyamurthy A and Balaram P 1999 J. Am. Chem. Soc. 121 5360

67. Banerjee A, Pramanik A, Bhattacharjya S and Balaram P 1996 Biopolymers 39769

68. (a) Hintermann T and Seebach D 1997 Chimia 51 244; (b) Frackenpohl J, Arvidsson P I, Schreiber J V and Seebach D 2002 Chem. Biochem. 2 445; (c) Rueping M, Mahajan Y, Sauer 
M and Seebach D 2002 Chem. Biochem. 3 257; (d) Gopi H N, Ravindra G, Pal P P, Pattanaik P, Balaram H and Balaram P 2003 FEBS Lett. 535175

69. Aravinda S, Shamala N, Das C, Sriranjini A, Karle I L and Balaram P 2003 J. Am. Chem. Soc. 1255308

70. Venkatraman J, Aggarwal K and Balaram P 2001 Chem. Biol. 8611

71. (a) Jarvo E R, Copeland G T, Papaioannou N, Bonitatebus Jr P J and Miller S J 1999 J. Am. Chem. Soc. 121 11638; (b) Copeland G T and Miller S J 2001 J. Am. Chem. Soc. 123 6496; (c) Guerin J and Miller S J 2002 J. Am. Chem. Soc. 1242134

72. Allen F H and Kennard O 1993 Chem. Des. Autom. News. 831 